\title{
Stability of the formation interface under the impact of hydraulic fracture propagation in the vicinity of the formation interface
}

\author{
Cong $\mathrm{Lu}^{1} \cdot$ Yun-Xiao $\mathrm{Lu}^{1,2} \cdot$ Jian-Chun Guo ${ }^{1} \cdot \mathrm{Li}^{-}$-ming $\mathrm{Liu}^{3}$
}

Received: 28 May 2019 / Published online: 13 January 2020

(c) The Author(s) 2020

\begin{abstract}
Unconventional hydrocarbon reservoirs in layered formations, such as tight sandstones and shales, are continually being developed. Hydraulic fracturing is a critical technology for the high-efficiency development of hydrocarbon reservoirs. Understanding the stress field and stability of the formation interface is vital to understanding stress propagation, preferably before the growing hydraulic fracture contacts the formation interface. In this study, models are developed for computing the stress field of hydraulic fracture propagation near the formation interface, and the stress fields within and at the two sides of the formation interface are analyzed. Four failure modes of the interface under the impact of hydraulic fracture propagation in its vicinity are identified, and the corresponding failure criteria are proposed. By simulating the magnitude and direction of peak stress at different parameters, the failure mode and stability of the formation interface are analyzed. Results reveal that when the interface strength is weak, the formation interface fails before the growing hydraulic fracture contacts it, and its stability is significantly related to a variety of factors, including the type of formation interface, rock mechanical properties, far-field stress, structural parameters, distance between the hydraulic fracture and formation interface, and fracturing execution parameters.
\end{abstract}

Keywords Formation interface $\cdot$ Fracture propagation $\cdot$ Stress field $\cdot$ Failure criterion $\cdot$ Stability

\section{List of symbols}

$a \quad$ Half fracture height (m)

$C \quad$ Distance between the hydraulic fracture and the formation interface $(\mathrm{m})$

$C_{\mathrm{s}} \quad$ Cohesion of the formation interface (MPa)

E Young's modulus (MPa)

$E_{1} \quad$ Young's modulus of the lower formation (MPa)

$E_{2} \quad$ Young's modulus of the upper formation (MPa)

Edited by Yan-Hua Sun

Cong Lu

lucong@swpu.edu.cn

$\triangle$ Jian-Chun Guo

guojianchun@vip.163.com

1 State Key Laboratory of Oil and Gas Reservoir Geology and Exploitation, Southwest Petroleum University, Chengdu 610500, China

2 Sinopec Shengli Petroleum Engineering Co., Ltd. Underground Operation Company, Dongying 257077, China

3 PetroChina Sichuan-Chongqing Shale Gas Front Command, Chengdu 610056, China
$F_{\text {oct }} \quad$ von Mises stress $(\mathrm{MPa})$

$g_{\mathrm{v}} \quad$ Friction pressure drop gradient in the fracture height direction $(\mathrm{MPa} / \mathrm{m})$

$g_{\mathrm{p}} \quad$ Fluid gravity gradient in the fracture height direction $(\mathrm{MPa} / \mathrm{m})$

$H \quad$ Depth of formation (m)

$k_{\mathrm{c}} \quad$ Consistency coefficient of the fracturing fluid $\left(\mathrm{Pa} \mathrm{s}^{n}\right)$

$K_{\mathrm{H}} \quad$ Structural coefficient in the direction of maximum principal stress

$K_{\mathrm{h}} \quad$ Structural coefficient in the direction of minimum horizontal principal stress

$L \quad$ Length of the hydraulic fracture (m)

$n \quad$ Behavior index of the fracturing fluid

$p_{\mathrm{f}} \quad$ Fluid pressure (MPa)

$Q \quad$ Pump rate $\left(\mathrm{m}^{3} / \mathrm{min}\right)$

$r_{\mathrm{sl}} \quad$ Radius of the plastic zone in the lower formation (m)

$R_{\mathrm{eH}} \quad$ Yield strength of upper rocks on the formation interface (MPa)

$R_{\mathrm{eL}} \quad$ Yield strength of lower rocks on the formation interface (MPa)

s Formation interface 
$\mathrm{s}_{1} \quad$ Lower formation

$\mathrm{s}_{2} \quad$ Upper formation

$T_{j} \quad$ Uniaxial tensile strength at one side of the formation interface $(\mathrm{MPa})$

$T_{1} \quad$ Uniaxial tensile strength at the lower side of the formation interface (MPa)

$T_{2} \quad$ Uniaxial tensile strength at the upper side of the formation interface (MPa)

$T_{\mathrm{s}} \quad$ Tensile strength of formation interface (MPa)

$\beta \quad$ Dip angle $\left(^{\circ}\right)$

$\theta \quad$ Angle between the hydraulic fracture and the formation interface $\left(^{\circ}\right)$

$\nu \quad$ Poisson's ratio

$\nu_{1} \quad$ Poisson's ratio of the lower formation

$\nu_{2} \quad$ Poisson's ratio of the lower formation

$\rho_{\mathrm{b}} \quad$ Overburden density $\left(\mathrm{kg} / \mathrm{m}^{3}\right)$

$\rho_{\mathrm{w}} \quad$ Formation fluid density $\left(\mathrm{kg} / \mathrm{m}^{3}\right)$

$\sigma \quad$ Normal stress (MPa)

$\sigma_{1 \mathrm{~h}} \quad$ Minimum horizontal principal stress in the lower formation (MPa)

$\sigma_{1 \mathrm{z}} \quad$ Vertical principal stress in the lower formation, $\mathrm{MPa}$

$\sigma_{2 \mathrm{~h}} \quad$ Minimum horizontal principal stress in the upper formation (MPa)

$\sigma_{2 \mathrm{z}} \quad$ Vertical principal stress in the upper formation (MPa)

$\sigma_{x x} \quad$ Normal stress in the $x$ direction $(\mathrm{MPa})$

$\sigma_{x y} \quad$ Shear stress $(\mathrm{MPa})$

$\sigma_{y y} \quad$ Normal stress in the $y$ direction $(\mathrm{MPa})$

$\sigma_{\mathrm{z}} \quad$ Vertical stress $(\mathrm{MPa})$

$\sigma_{\max } \quad$ Maximum normal stress (MPa)

$\sigma_{\text {min }} \quad$ Minimum normal stress $(\mathrm{MPa})$

$\sigma_{\mathrm{s} x x}\left(r_{1}\right) \quad$ Normal stress in the $x$ direction near the fracture tip in the lower formation (MPa)

$\sigma_{\text {syy }}\left(r_{1}\right) \quad$ Normal stress in the $y$ direction near the fracture tip in the lower formation (MPa)

$\sigma_{\text {sxy }}\left(r_{1}\right)$ Shear stress near the fracture tip in the lower formation $(\mathrm{MPa})$

$\sigma_{1 x x} \quad$ Normal stress in the $x$ direction in the lower formation (MPa)

$\sigma_{1 y y} \quad$ Normal stress in the $y$ direction in the lower formation (MPa)

$\sigma_{1 x y} \quad$ Shear stress in the lower formation (MPa)

$\sigma_{2 x x} \quad$ Normal stress in the $x$ direction in the upper formation (MPa)

$\sigma_{2 y y} \quad$ Normal stress in the $y$ direction in the upper formation (MPa)

$\sigma_{2 x y} \quad$ Shear stress in the upper formation (MPa)

$\sigma_{\mathrm{s} 1} \quad$ Uniaxial tensile yield stress of the rock in the lower formation (MPa)

$\tau_{\mathrm{s}} \quad$ Shear stress of formation interface (MPa)

$\tau_{\mathrm{sl}} \quad$ Shear yield stress of rock in the lower formation (MPa) $\varphi \quad$ Peak angle of internal friction $\left(^{\circ}\right)$

$\varphi_{\mathrm{s}} \quad$ Angle of internal friction of the formation interface $\left(^{\circ}\right)$

\section{Introduction}

Hydraulic fracturing is a critical technology for the highefficiency development of unconventional hydrocarbon reservoirs, such as tight sandstones and shale gas. Many unconventional hydrocarbon reservoirs occur in formations with clear interfaces, such as stratified formations and formations interlaced with sand-mud beddings. A formation interface complicates the mechanism of hydraulic fracture propagation, owing to the difference in pressure, rock material properties, interfacial strength, interfacial morphology, and rock failure behavior between the two sides of the formation interface (Guo et al. 2017; Li et al. 2018; Lu et al. 2015; Tang et al. 2019). When hydraulic fractures extend to the vicinity of the formation interface but do not contact the formation interface, it can be considered that the hydraulic fractures are propagated in a homogeneous medium. Whereas the fracture is not in contact with the formation interface, the stress field of the fracture propagation interacts with it. When the resulting stress is large enough at the formation interface, the formation interface deforms and fails. The deformation and failure of the formation interface significantly influence fracture propagation, particularly in the height direction (Arash and Olson 2013; Bunger et al. 2012; Cohen et al. 2017; Jeffrey and Bunger 2009; Wang 2015, Wang et al. 2015). Therefore, it is necessary to analyze the stability of the formation interface under the impact of hydraulic fracture propagation in the vicinity of the formation interface.

Renshaw and Pollard (1995) suggested discontinuous fracture propagation across formation interfaces under the condition of small-range yields. More specifically, when a fracture impinges upon a formation interface oriented normal to the growing fracture, a new fracture can initiate at the other side of the formation interface. However, the old and new fractures do not form a continuous fracture. $\mathrm{Wu}$ et al. (2004) developed a fracture mechanism map, in which the behavior of a fracture propagating in the vicinity of a formation interface was considered. They found that a fracture propagating in the vicinity of an interface could induce a new fracture at the other side of the formation interface or bend. It may propagate in different morphologies simultaneously. They also found that, when in contact with the formation interface, the growing fracture could terminate at or cross the formation interface or propagate along it. Their subsequent experimental observations verified the above mechanisms. Their research results expanded the understanding of the mechanism of fracture propagation 
interacting with the formation interface. Stratum stress is a major factor influencing fracture propagation. When propagating from a lower-stress stratum to a higher-stress stratum, a fracture changes its direction in most cases. It usually breaks through the formation interface and terminates after propagating for a small distance (Warpinski and Teufel 1987; Zhao et al. 2009). When a fracture propagates near but does not contact an interface, the stress field at the fracture tip is the same as that in the case of a fracture propagating in a single-phase material (Irwin 1957). When a fracture propagates in a two-phase material, and the material surrounding the fracture tip is a single-phase material, the stress field at the fracture tip always has the singularity of $r^{-1 / 2}$ (Kuang and Ma 2002). Lithological properties affect the behavior of a fracture propagating in the vicinity of a formation interface. However, they are not enough to explain fracture propagation in the vicinity (Daneshy 1978). Lithological properties affect the distribution of the stress field and the width of the fracture (Ham 1982). For a fracture propagating from a stratum with a lower Young's modulus to a stratum with a higher Young's modulus, the stress intensity factor decreases when the fracture approaches the formation interface and rapidly increases after it breaks through the formation interface (Hanson and Shaffer 1980). The difference in material properties between the two sides of the formation interface complicates the fracture propagation mechanism (Wu et al. 2004).

Many theoretical studies have been published on hydraulic fracture growth and containment in layer media (Chen et al. 2017; Damani et al. 2018; Garavand and Podgornov 2018; Ouchi et al. 2017a, b; Oyedokun and Schubert 2017; Paul et al. 2018; Tang and Wu 2018; Wang 2015, Wang et al. 2015; Zeng et al. 2018; Zhang et al. 2018). Fisher and Warpinski (2012) indicated that weak interfaces are regarded as a significant factor in stopping fracture height growth at shallow depths, initiating interface fractures or creating offsets along the interface. Rutledge et al. (2014) presented a model with step-over features to describe the sliding along the bedding interface which was driven by the opening of the vertical fracture. Chuprakov and Prioul (2015) elaborated a FracT model which can solve the problem of elastofrictional fracture contact with weak horizontal interfaces. Cohen et al. (2017) proposed a new stacked height growth model (SHG), regarded as an enhanced pseudo-3D model (P3D), to model the effect of ledges at weak interfaces. Izadi et al. (2017) developed a fully coupled 3D hydraulic fracturing simulator to investigate interference of multiple fractures with consideration of the effect of bedding planes. Tang and Wu (2018) introduced a fully three-dimensional displacement discontinuity method (3D DDM) to model multiple fractures in three dimensions under the influence of weak interfaces.
Anderson (1981) observed the existence of critical normal stress through the interface in multi-layer fracture propagation simulation experiment. He proposed to use critical normal stress to judge whether the fracture passes through the interface. Biot et al. (1983) assumed that the fracture is shaped like a sine function and deduced the expression of the pressure inside the fracture when the fracture does or does not pass through the interface with the principle of virtual work, and by comparison of which, they proposed to judge whether the fracture has passed through the interface by the product of the surface energy and elasticity modulus of the fracture. Warpinski and Teufel (1987) proposed that the fracture propagates along the interface when the shear stress on the tip of the fracture paralleling to the interface is larger than the shear strength of the interface. He and Hutchinson (1989) proposed a method for judging whether a fracture passes through an interface by the energy release rate of the fracture tip. Renshaw and Pollard (1995) proposed two conditions for the crack to pass through the interface, one is that the tensile stress at the interface of the crack tip is greater than the tensile strength of the interface, and the other is that the shear stress at the crack tip along the interface is less than the shear strength of the interface. A stress analysis reported by Wu et al. (2004) suggests plane/straight fracture propagation when a fracture grows from a stiff to a soft material. Depending on the specifics of a given problem, an amount of fracture behavior can arise when a fracture propagates from a soft to a stiff material. Such behavior includes crack arrest at the interface, plane fracture growth, fracture kinking, interface delamination, and formation of secondary fractures. Some experimental evidences of these fracture behavior are reported in Wu et al. (2004) as well.

Researchers have done a lot of very valuable work on the fracture propagation model for layered formations. However, there is little concern about the stress field at the interface considering the heterogeneity of the formation, tip plastic zone and the dip angle of the formation, especially when the fracture does not touch the formation interface. In addition, the expansion criteria for fracture propagation to the interface are more complex than homogeneous formations due to the diversity of the expansion criteria. For this study, a model, considering the differences in rock mechanical properties on both sides of the formation interface and the influence of formation dip, was developed for computing the stress field of hydraulic fracture propagation near the formation interface. The effect of the plastic zone at the hydraulic fracture tip on the formation interface is discussed, and the stress fields within the formation, at the formation interface, and at the two sides of the formation interface are analyzed. The study identifies four failure modes of the formation interface under the impact of hydraulic fracture propagation in the vicinity of the formation interface and proposes corresponding failure criteria. Finally, the effect of different 
parameters (e.g., rock mechanical parameters, dip angle, distance between the hydraulic fracture and the formation interface, pump rate) on the failure mechanism and stability of the formation interface is analyzed.

\section{Analysis of the stress field of fracture propagation near the formation interface}

Lu et al. (2016) established a stress-field calculation model for propagating hydraulic fractures at the formation interfaces based on the complex variable function method and fracture mechanics theory. The propagation of hydraulic fractures at the formation interface was simplified to facilitate the computation, as shown in Fig. 1 (Lu et al. 2016).

Based on the superposition principle, the propagation of the hydraulic fracture at the formation interface can be defined as the superposition of three issues: the fluid pressure $p_{\mathrm{f}}$ in the hydraulic fracture without far-field stress; that with far-field stress and without hydraulic fracture; and the self-balancing surface force on the surface of the hydraulic fracture without far-field stress.

Using the superposition principle, a model is obtained to calculate the extended stress field of hydraulic fracture at the interface of the formation, and the corresponding Cauchy singular integral equations are established. The numerical solution is proposed based on the Lobatto-Chebyshev quadrature method. The simplified model and the stress field calculation model of the type I Griffith crack subjected to

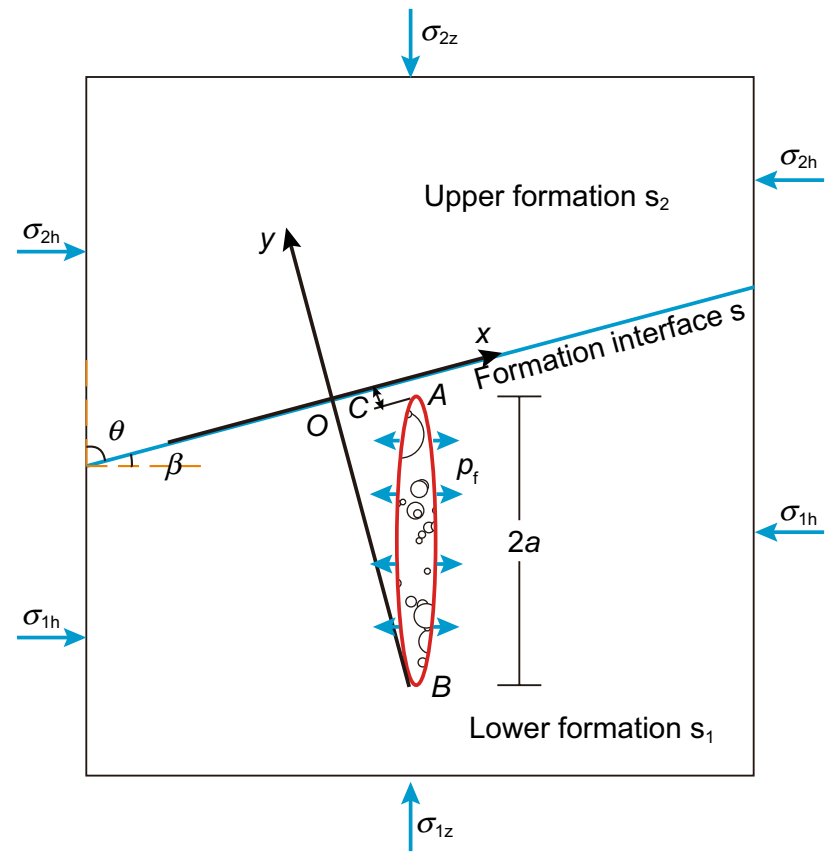

Fig. 1 Simplified diagram of the geometric model. Modified from $\mathrm{Lu}$ et al. (2016) the uniaxial tension problem show that the model is correct and reliable.

\subsection{Plastic zone at the hydraulic fracture tip}

To avoid the effect of stress singularity, we assume that there exists plastic yield in a small zone at the fracture tip (Fig. 2). A hydraulic fracture propagating in the vicinity of a formation interface can be taken as one in a homogeneous medium. Thus, only the plastic zone at the fracture tip in the lower stratum is analyzed. The von Mises yield criterion was used to determine the size of the plastic zone at the hydraulic fracture tip:

$\left[\sigma_{\mathrm{s} x x}\left(r_{1}\right)-\sigma_{\mathrm{s} y y}\left(r_{1}\right)\right]^{2}+6\left[\sigma_{\mathrm{s} x y}\left(r_{1}\right)\right]^{2}=2 \sigma_{\mathrm{s} 1}^{2}=6 \tau_{\mathrm{s} 1}^{2}$

Assuming that the rock in the plastic zone is in an idealized plastic status, the stress in the rock is smaller than or equal to the stress at the boundary of the plastic zone $(\mathrm{Gu}$ et al. 2012). The stress field at the formation interface is computed using the models for computing the stress field of hydraulic fracture propagation in the vicinity. The radius of the plastic zone at the fracture tip is then determined using Eq. (1). The distance between the hydraulic fracture and the formation interface is set to $0.5 \mathrm{~m}$, and the other parameters are set to values given by Lu et al. (2016), as shown in Table 1.

As shown in Fig. 3, the plastic zone at the hydraulic fracture tip is small, when the growing hydraulic fracture is not in contact with the formation interface. Its boundary is not in contact with the formation interface, and it has a small effect on the stress field at the formation interface. Therefore, the effect of the plastic zone at the fracture tip is not considered in the examination of hydraulic fracture propagation in the

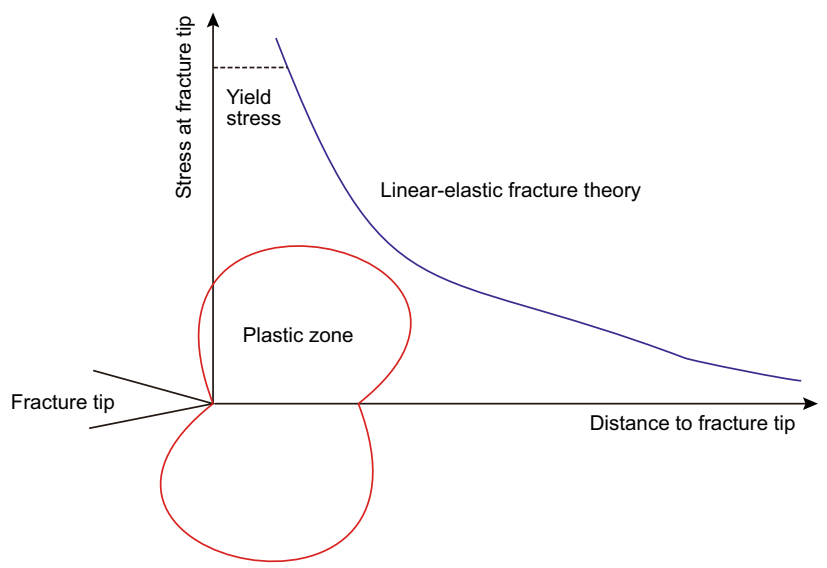

Fig. 2 Plastic zone at fracture tip (Fan 1978) 
Table 1 Basic parameters for the computation

\begin{tabular}{ll}
$E_{2} / E_{1}, \mathrm{MPa} / \mathrm{MPa}$ & $\begin{array}{l}20,000 / 30,000 \\
\nu_{2} / \nu_{1}\end{array}$ \\
Distance between the hydraulic fracture and the formation interface $C, \mathrm{~m}$ & $0.3 / 0.2$ \\
Dip angle $\beta,\left(^{\circ}\right)$ & 0 \\
Formation depth $H, \mathrm{~m}$ & 2,000 \\
Overburden density $\rho_{\mathrm{b}}, \mathrm{kg} / \mathrm{m}^{3}$ & $2.0 \times 10^{3}$ \\
Formation fluid density $\rho_{\mathrm{w}}, \mathrm{kg} / \mathrm{m}^{3}$ & $0.8 \times 10^{3}$ \\
Structural coefficient in the direction of maximum principal stress $K_{\mathrm{H}}$ & $4 \times 10^{-7}$ \\
Structural coefficient in the direction of minimum horizontal principal stress $K_{\mathrm{h}}$ & 0.8 \\
Consistency coefficient of the fracturing fluid $k_{\mathrm{c}}$, Pa s ${ }^{n}$ & 0.2 \\
Behavior index of the fracturing fluid $n$ & 0.85 \\
Length of the hydraulic fracture $L, \mathrm{~m}$ & 100 \\
Height of the hydraulic fracture $2 a, \mathrm{~m}$ & 20 \\
Friction pressure drop gradient in the fracture height direction $g_{\mathrm{v}}, \mathrm{MPa} / \mathrm{m}$ & 0.02 \\
Fluid gravity gradient in the fracture height direction $g_{\mathrm{p}}, \mathrm{MPa} / \mathrm{m}$ & 0.01 \\
Pump rate $Q, \mathrm{~m}^{3} / \mathrm{min}$ & 5 \\
Yield strength of upper rocks on the formation interface $R_{\mathrm{eH}}, \mathrm{MPa}$ & 12 \\
Yield strength of lower rocks on the formation interface $R_{\mathrm{eL}}, \mathrm{MPa}$ & 15 \\
\hline
\end{tabular}

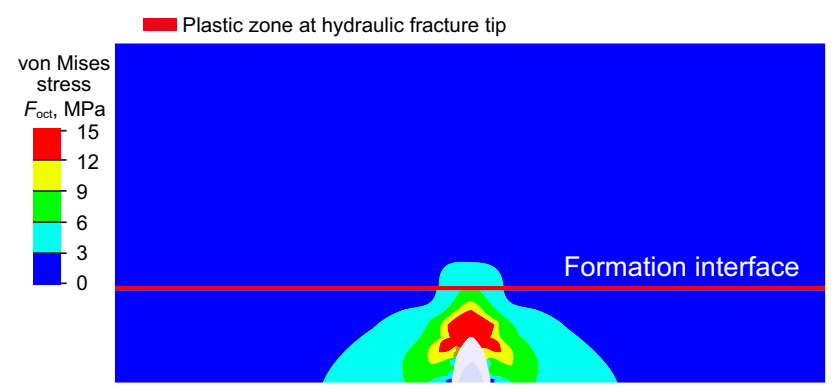

Fig. 3 Plastic zone at the tip of a hydraulic fracture propagating in the vicinity of a formation interface

vicinity of formation interface. Instead, the stress field at the formation interface is directly analyzed and computed.

\subsection{Analysis of the stress field}

The stress field of hydraulic fracture propagation in the vicinity of formation interface is computed using the models proposed above. The maximum principal stress, normal stress, and shear stress at the formation interface are then analyzed separately for their distribution characteristics.

\subsubsection{Within-formation stress fields}

Table 1 shows the parametric setting for the computation. A computational program was written in the MATLAB software to compute the maximum normal stress field and shear stress field in the formation and the stress field normal to the

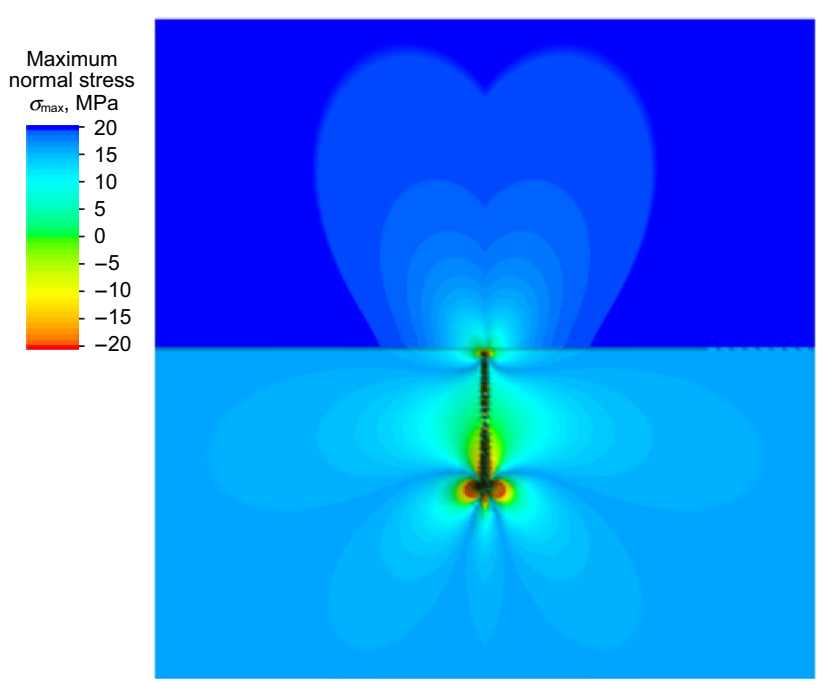

Fig. 4 Maximum normal stress fields in the formation

formation interface. The computation step length was $0.1 \mathrm{~m}$. Figures 4, 5 and 6 show the computational results.

The within-formation stress fields of hydraulic fracture propagation in the vicinity of the formation interface have the following characteristics:

- A stress field with stress concentration was induced around the hydraulic fracture. As the effect of the plastic zone at the fracture tip was neglected, the fracture tip exhibited stress singularity. 


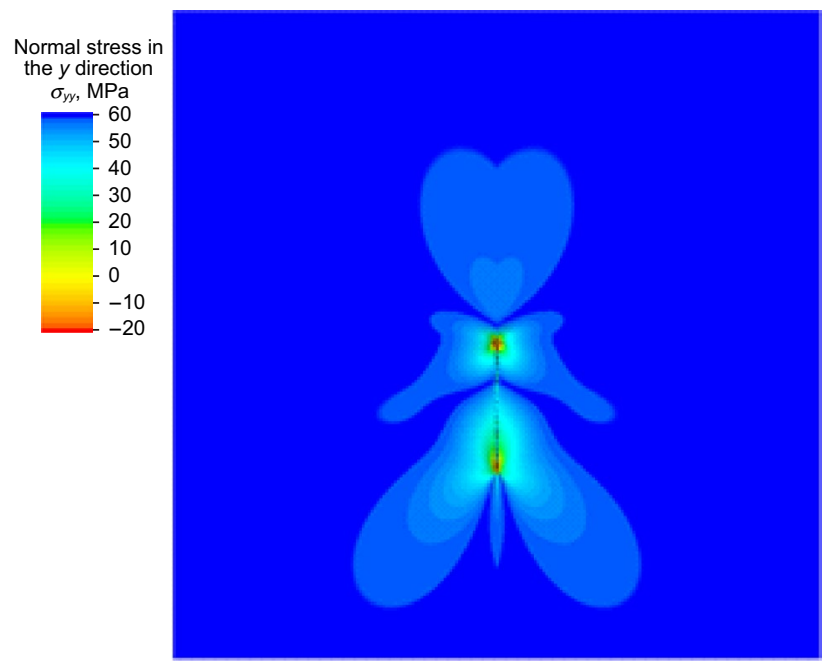

Fig. 5 Normal stress fields in the strata

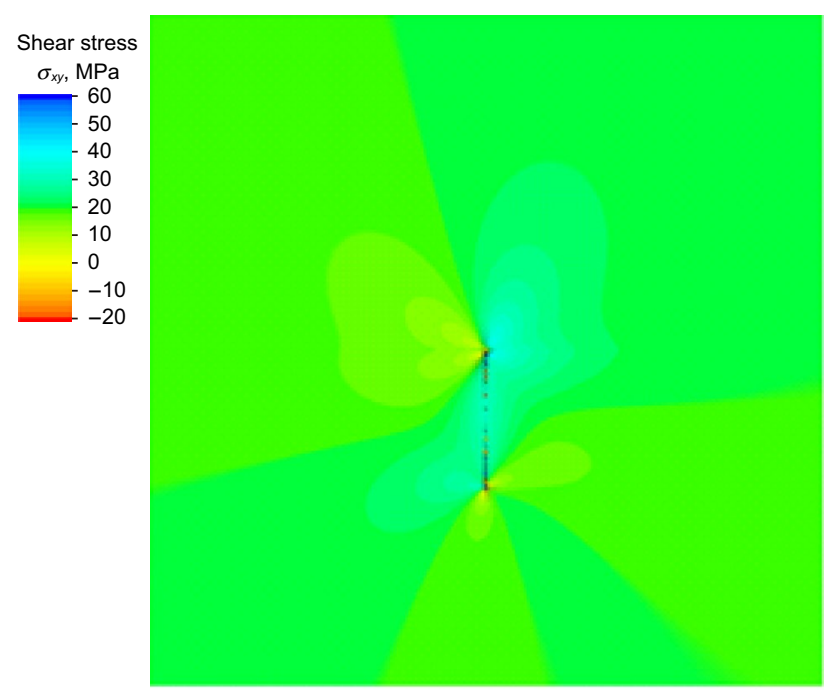

Fig. 6 Shear stress fields in the strata

- The maximum normal stress field and normal stress field are symmetric, whereas the shear stress field is antisymmetric.

- As the distance to the hydraulic fracture increases, the maximum normal stress field and normal stress field gradually transit from tensile to compressive. The direction of the shear stress in the formation changes with the angle relative to the hydraulic fracture.

\subsubsection{Stress field at the formation interface}

Assuming the hydraulic fracture propagation remains within the lower stratum, the stress field of the upper and lower strata of the interface under different rock mechanical properties is calculated. The variation trends of the stresses at the two sides of the formation interface are then computed. When there is a difference between the upper and lower sides, we define that the pay layer has a high Young's modulus and a low Poisson's ratio, correspondingly, the barrier is just the opposite. When there is no difference between the upper and lower sides, the rock mechanical properties are the same. Table 2 shows the setting for rock mechanical parameters used in the computation. The setting for other parameters is shown in Table 1. Figures 7, 8 and 9 show the computational results.

The stress fields at the two sides of the formation interface resulting from hydraulic fracture propagation in the vicinity of the formation interface have the following distribution characteristics:

- When the upper side and the lower side are of different properties, the maximum normal stresses, normal stresses, and shear stresses at the two sides of the formation interface vary at different slopes. The stress-change rate in the side with high Young's modulus and low Poisson's ratio is bigger than that in the side with low Young's modulus and high Poisson's ratio.

- The maximum normal stresses at the two sides of the formation interface are discontinuous. The maximum tensile stress at the pay-layer side of the formation interface is bigger than that at the barrier-side of the formation interface. This indicates that the pay layer has a higher tendency of tensile failure than the barrier bed, and the barrier bed serves to contain fracture propagation in the height direction. The discontinuous distribution of the maximum normal stresses is caused by the difference in stress between the pay layer and the barrier bed and the discontinuous stresses induced at the two sides of the formation interface. Therefore, the lower and upper strata

Table 2 Setting for rock mechanical parameters for different configurations

\begin{tabular}{llllll}
\hline Configuration of pay layer and barrier bed & \multicolumn{2}{l}{ Young's modulus $E, \mathrm{MPa}$} & & \multicolumn{2}{c}{ Poisson's ratio $v$} \\
\cline { 2 - 3 } & Lower stratum & Upper stratum nner stratum & & Lower \\
\hline Hydraulic fracture within pay layer & 30,000 & 20,000 & 0.20 & 0.30 \\
Hydraulic fracture within barrier bed & 20,000 & 30,000 & 0.30 & 0.20 \\
No difference between pay layer and barrier bed & 30,000 & 30,000 & 0.25 & 0.25 \\
\hline
\end{tabular}




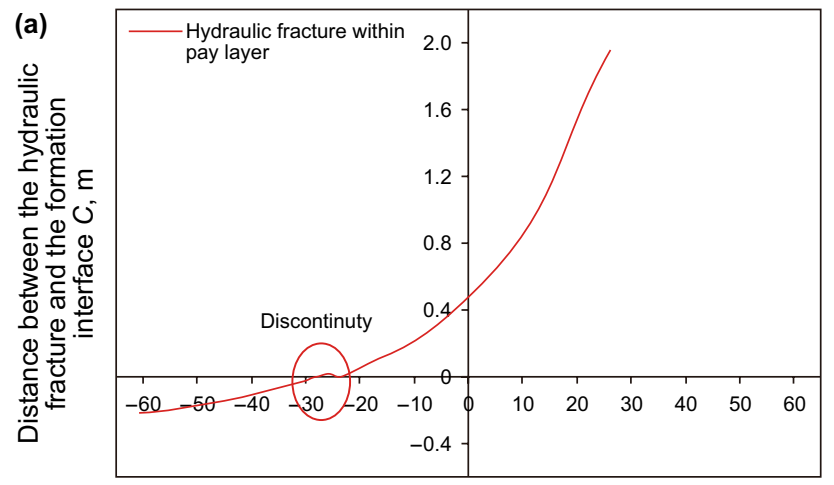

Maximum normal stress $\sigma_{\max }, \mathrm{MPa}$

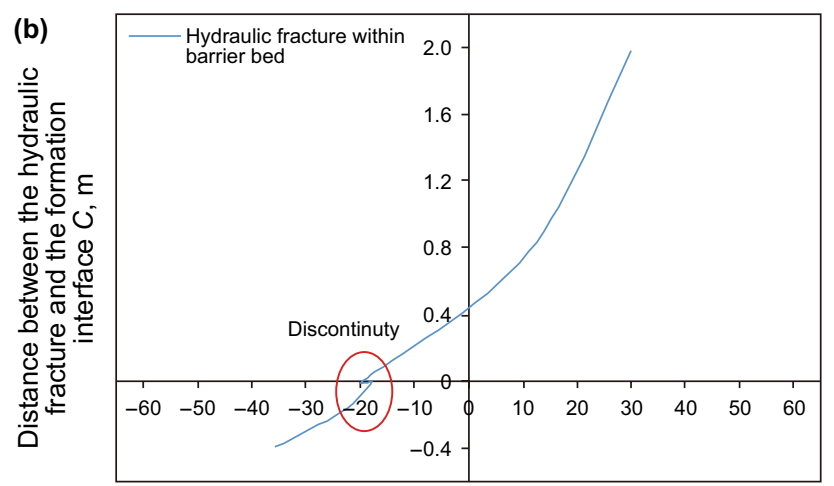

Maximum normal stress $\sigma_{\max }, \mathrm{MPa}$

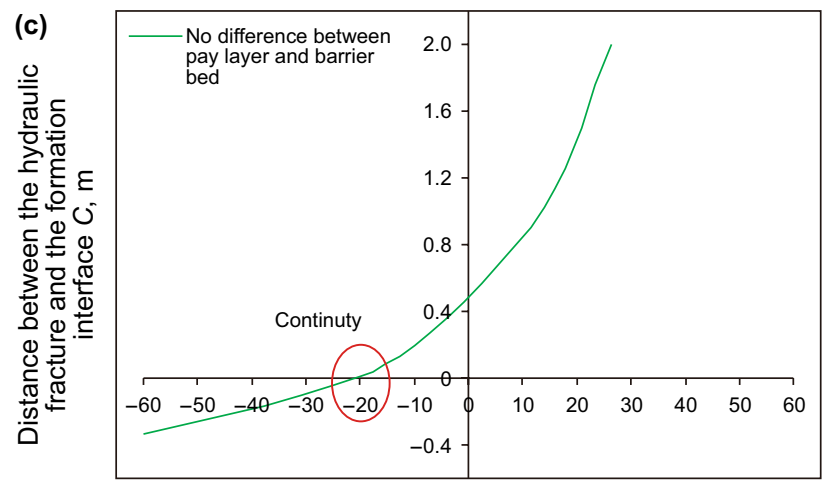

Maximum normal stress $\sigma_{\max }, \mathrm{MPa}$

Fig. 7 Maximum normal stress fields at the two sides of the formation interface under different rock mechanical parameters. a Hydraulic fracture within the pay layer. b Hydraulic fracture within the barrier bed. $\mathbf{c}$ No difference between pay layer and barrier bed

of the formation interface should be examined separately for the occurrence of tensile failure.

- As the distance to the hydraulic fracture increases, the within-formation maximum normal stress field and normal stress field gradually transit from tensile to compressive. This indicates the reversal of the stresses at the two sides of the formation interface. As the distance to the hydraulic fracture increases, the stresses at the two sides

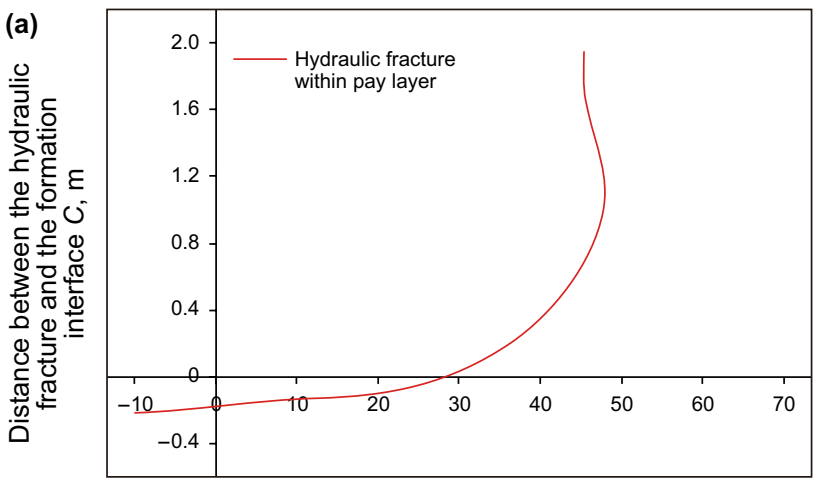

Normal stress $\sigma_{y y}, \mathrm{MPa}$

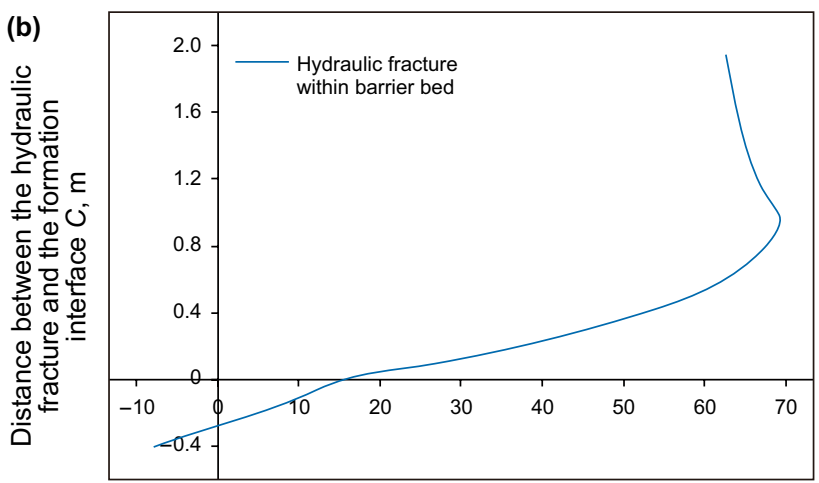

Normal stress $\sigma_{y y}, \mathrm{MPa}$

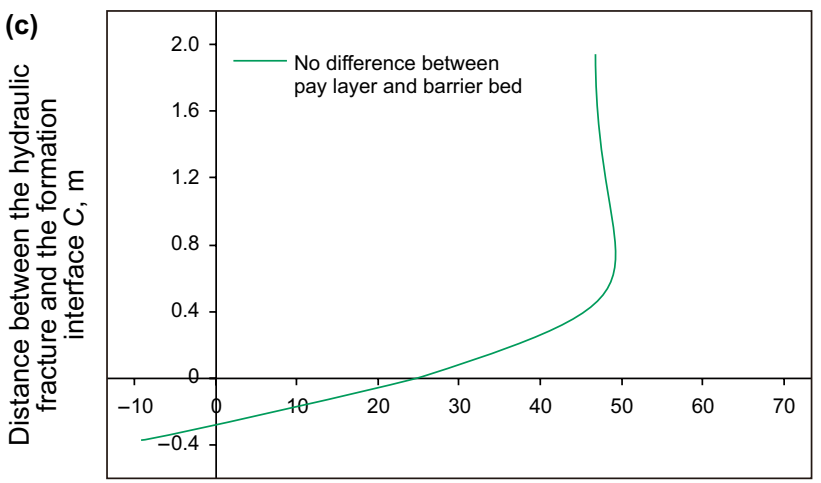

Normal stress $\sigma_{y y}, \mathrm{MPa}$

Fig. 8 Normal stress fields at the two sides of the formation interface under different rock mechanical parameters. a Hydraulic fracture within the pay layer. b Hydraulic fracture within the barrier bed. $\mathbf{c}$ No difference between pay layer and barrier bed

of the formation interface gradually recover to the corresponding far-field stresses.

\subsubsection{Stress fields at the two sides of the formation interface}

When the rocks at the two sides of the formation interface are of different properties, the maximum normal stresses 

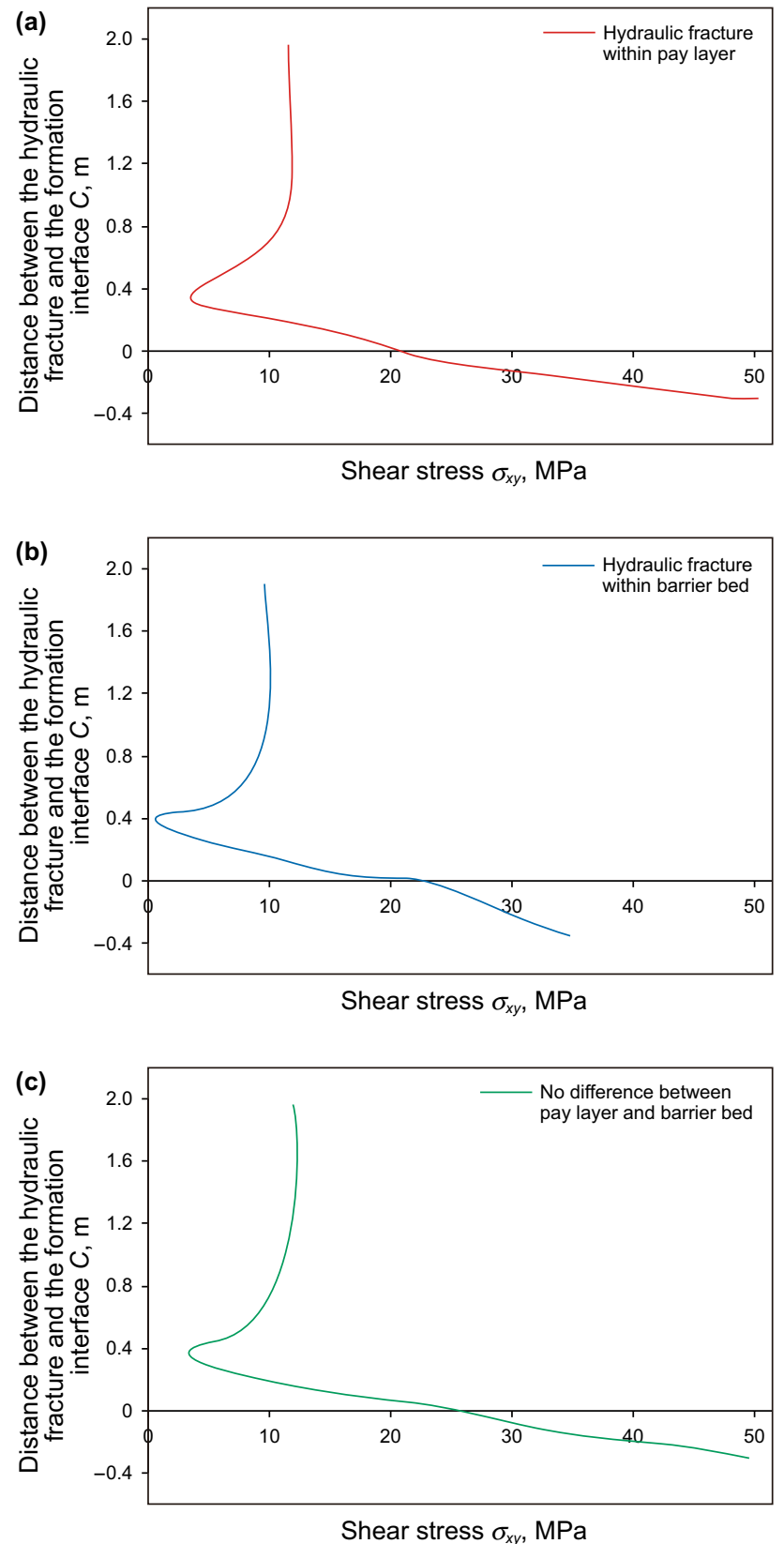

Fig. 9 Shear stress fields at the two sides of the formation interface under different rock mechanical parameters. a Hydraulic fracture within pay layer. b Hydraulic fracture within barrier bed. c No difference between pay layer and barrier bed

at the formation interface are discontinuous. Therefore, the stress fields at the upper and lower sides of the formation interface should be computed separately for analyzing the stress field. The normal compressive stress and shear stress are continuous at the formation interface. Thus, their distributions at only one side should be analyzed. Figures 10, 11, $12,13,14,15$ and 16 show the computational results.

At a dip angle of $0^{\circ}$, the stress fields at the formation interface have the following distribution characteristics:
- The maximum tensile stress at the lower side of the formation interface is bigger than that at the upper side. At a point in the formation interface far away from the hydraulic fracture tip, the difference between the maximum normal stresses at the upper and lower sides of the formation interface is equal to the difference between the far-field stresses of the pay layer and barrier bed.

- The maximum normal stress and normal stress distribute symmetrically around the hydraulic fracture. The tensile stress peaks at a point right above the hydraulic fracture. The shear stress exhibits an approximately antisymmetric distribution around the hydraulic fracture and peaks at a point slightly deviating from the normal direction of the hydraulic fracture

- The minimum normal stress exhibits an antisymmetric distribution around the hydraulic fracture. More specifically, the minimum normal stress right above the hydrau-

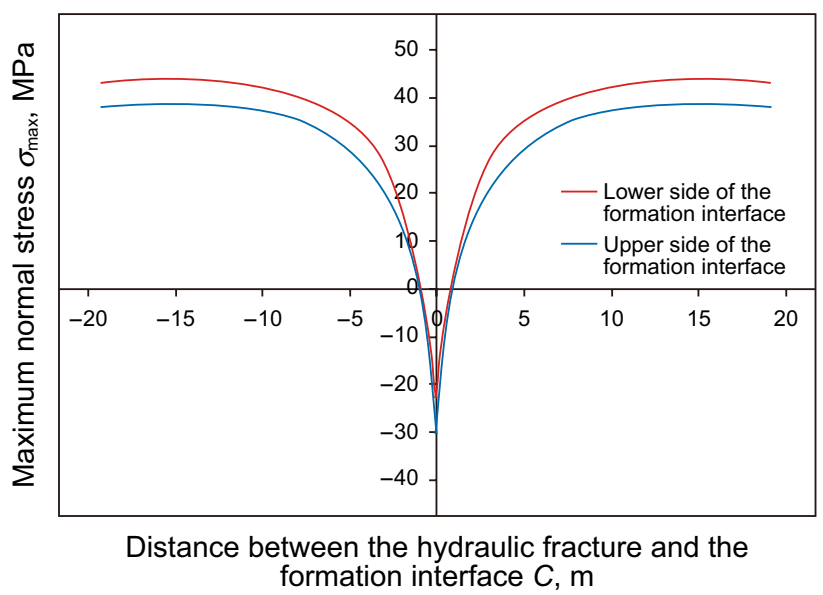

Fig. 10 Maximum normal stress at the formation interface at a dip angle of $0^{\circ}$

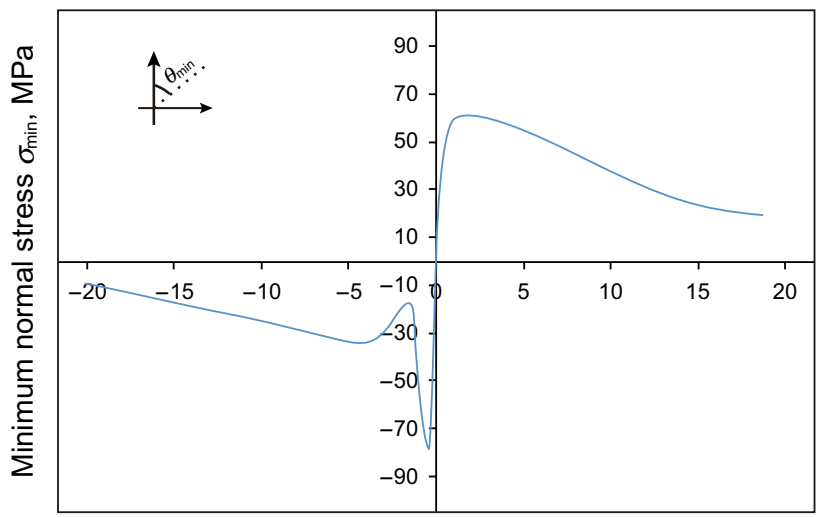

Distance between the hydraulic fracture and the formation interface $C, \mathrm{~m}$

Fig. 11 Direction of minimum normal stress at the formation interface at a dip angle of $0^{\circ}$ 


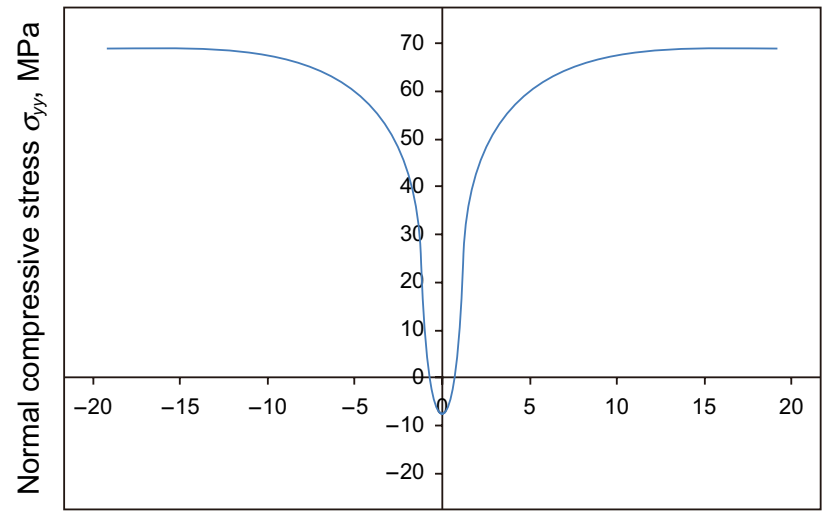

Distance between the hydraulic fracture and the formation interface $C, \mathrm{~m}$

Fig. 12 Normal compressive stress at the formation interface at a dip angle of $0^{\circ}$

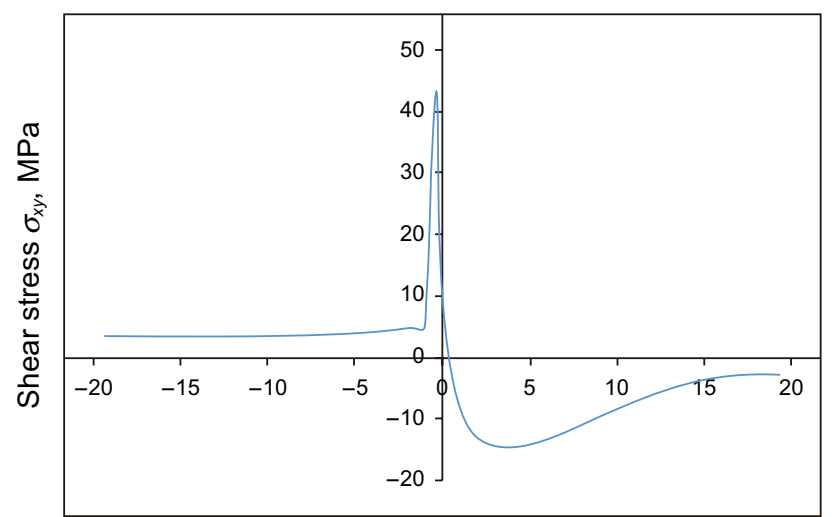

Distance between the hydraulic fracture and the formation interface $C, \mathrm{~m}$

Fig. 13 Shear stress at the formation interface at a dip angle of $0^{\circ}$

lic fracture is perpendicular to the formation interface. As the distance to the hydraulic fracture increases, the direction of the minimum normal stress rotates to the direction parallel to the formation interface.

- As the distance between formation interface and hydraulic fracture increases, the normal stress gradually transits from tensile to compressive; the shear stresses at the two sides of the hydraulic fracture are in reverse directions and gradually recover to the corresponding far-field stresses.

As shown in Figs. 14,15 and 16, at a dip angle of $45^{\circ}$, the maximum normal stress and normal compressive stress at the formation interface still exhibit symmetric, single-peak, and stress-reversal distributions. The shear stress at the formation interface still exhibits an antisymmetric, single-peak,

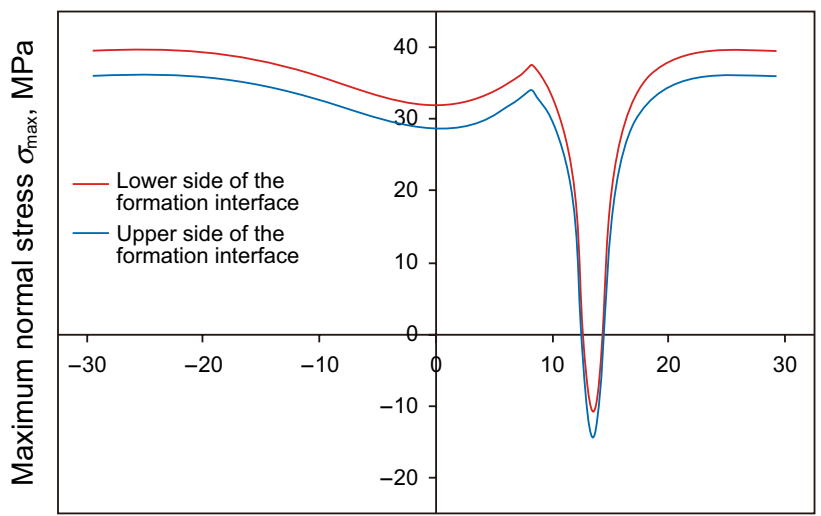

Distance between the hydraulic fracture and the formation interface $\mathrm{C}, \mathrm{m}$

Fig. 14 Maximum normal stress at the formation interface at a dip angle of $45^{\circ}$

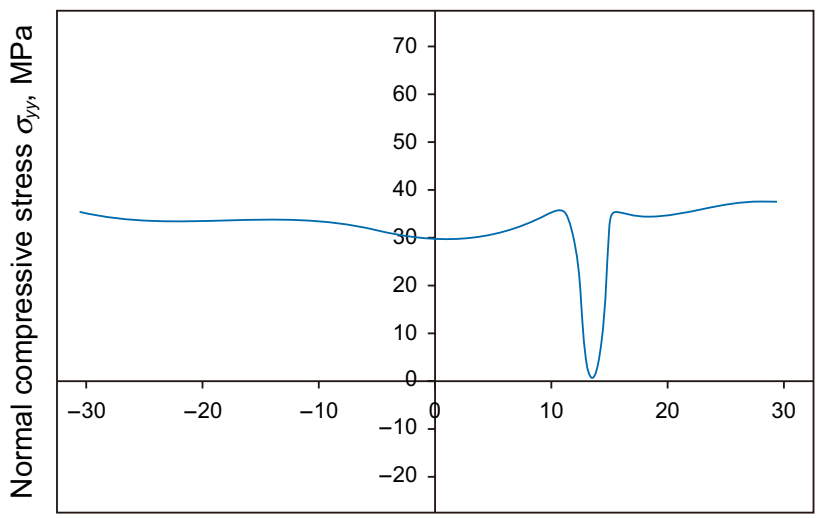

Distance between the hydraulic fracture and the formation interface $C, \mathrm{~m}$

Fig. 15 Normal compressive stress at the formation interface at a dip angle of $45^{\circ}$

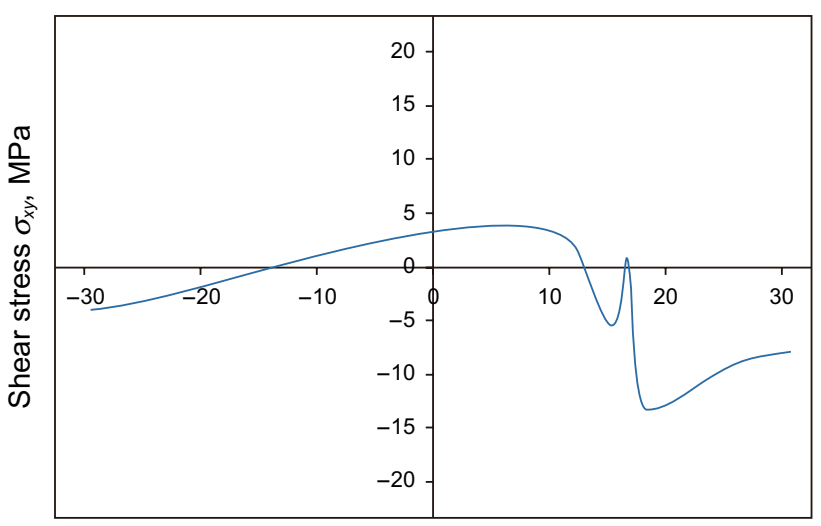

Distance between the hydraulic fracture and the formation interface $C, \mathrm{~m}$

Fig. 16 Shear stress at the formation interface at a dip angle of $45^{\circ}$ 
and stress-reversal distribution. Note that, at a dip angle of $45^{\circ}$, the transition of the stress field at the formation interface is caused by the change in the position of the hydraulic fracture relative to the formation interface, and this does not affect the results of the stress-field analysis.

\section{Criteria for determining the failure of the formation interface}

Under the effect of the stress field caused by hydraulic fracture propagation near the formation interface, the formation interface may experience four different modes of failure: Type A failure (Fig. 17a), where tensile failure occurs at either or both sides of the formation interface with new fractures initiating at either or both sides of the formation interface; Type B failure (Fig. 17b), where shear failure occurs at the formation interface, resulting in a slip; Type $\mathrm{C}$ failure (Fig. 17c), where tensile failure occurs at the formation interface, with new fractures initiating at it; and complex failure (Type D failure) (Fig. 17d), where failure occurs at the formation interface and at either side of it, and the failure is a result of the occurrence of two or more of the above failure modes.

The above four failure modes are related to the magnitude of the stress acting on the formation interface and the criteria for determining the failure modes.

\subsection{Criteria for tensile failure at either or both sides of the formation interface}

Tensile failure of the rocks at either or both sides of the formation interface (i.e., Type A failure) can be determined using the maximum normal stress intensity theory. However, because the theory is only applicable to tensile status under two-dimensional stress conditions, its application to hydraulic fracture propagation near the formation interface requires the condition that the maximum principal stress acting on it be tensile and have a negative value.



(a) Type A failure

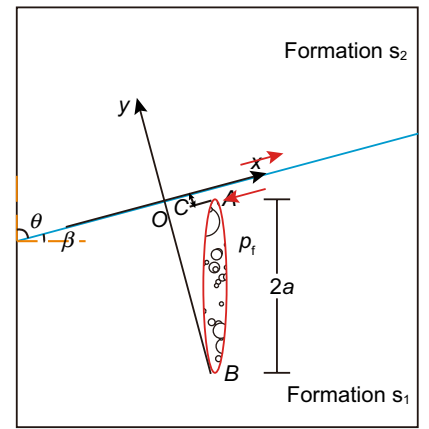

(b) Type B failure

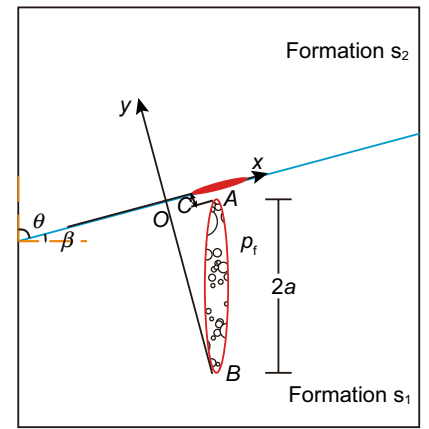

(c) Type $C$ failure

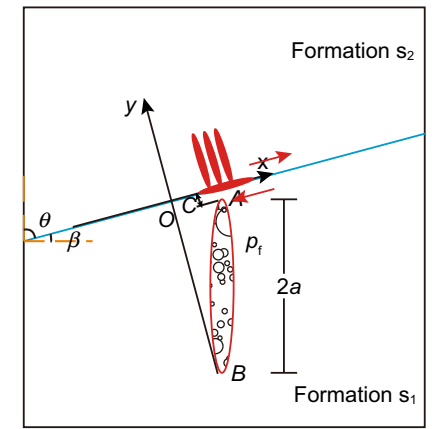

(d) Complex failure

When the tensile failure occurs at either side of the formation interface, the propagation direction of the new fracture developing at it is the same as the direction of the minimum principal stress. The propagation direction of the new fracture developing in the upper stratum can be computed using the following equation:

$$
\tan 2 \theta_{2}=\frac{2 \sigma_{2 x y}}{\sigma_{2 x x}-\sigma_{2 y y}}
$$

Fig. 17 Potential failure modes of a formation interface under the impact of hydraulic fracture propagation near the formation interface 


\subsubsection{Tensile failure at both sides of the formation interface}

The tensile failure at both sides of the formation interface, designated as a Type $\mathrm{A}_{12}$ failure, can be determined by the following equation:

$\left.\begin{array}{l}\frac{\sigma_{1 x x}+\sigma_{1 y y}}{2}-\sqrt{\left(\frac{\sigma_{1 x x}-\sigma_{1 y y}}{2}\right)^{2}+\sigma_{1 x y}^{2}}<-T_{1} \\ \frac{\sigma_{2 x x}+\sigma_{2 y y}}{2}-\sqrt{\left(\frac{\sigma_{2 x x}-\sigma_{2 y y}}{2}\right)^{2}+\sigma_{2 x y}^{2}}<-T_{2}\end{array}\right\}$

The propagation direction of the new fractures developing at the two sides of the formation interface can be determined using Eqs. (3) and (5).

\subsection{Shear failure of the formation interface}

The shear failure at the formation interface, Type B failure, can be determined using the Mohr-Coulomb failure criterion (Xie and Chen 2004). According to the single-planeof-weakness theory, the presence of a formation interface in rock mass results in the anisotropy of the rock mass in the height direction (Liu et al. 2013). Thus, when the shear failure occurs at the formation interface, the rock mass has the smallest shear strength, equalling the shear strength of the formation interface. Therefore, it is appropriate to use the Mohr-Coulomb failure criterion to determine whether the shear failure has occurred at the formation interface. A shear stress acts on the formation interface, satisfying the following equation:

$\sigma_{x y}>\sigma_{y y} \tan \varphi_{\mathrm{s}}+C_{\mathrm{s}}$

The shear failure of the formation interface is related to the shear stress and normal stress acting on the formation interface.

\subsection{Tensile failure of the formation interface}

The tensile failure at the formation interface is designated a Type $\mathrm{C}$ failure. Under normal stress, it experiences a normal deformation. When the normal stress is tensile, the formation interface experiences tensile failure. Like the maximum normal stress intensity theory, the failure criterion of the rock is:

$\sigma_{y y}<-T_{\mathrm{s}}$

Note that this failure criterion is also based on the condition that the normal stress acting on the formation interface is tensile and has a negative value.

\subsection{Complex failure}

The complex failure is designated as a Type D failure. When the stress acting on the formation interface satisfies two or more failure criteria, the formation interface and the other side of the formation interface experience complex failure. The criteria for determining the complex failure can be expressed as Eqs. (9)-(18):

$$
\left.\begin{array}{l}
\frac{\sigma_{1 x x}+\sigma_{1 y y}}{2}-\sqrt{\left(\frac{\sigma_{1 x x}-\sigma_{1 y y}}{2}\right)^{2}+\sigma_{1 x y}^{2}}<-T_{1} \\
\frac{\sigma_{1 x x}+\sigma_{1 y y}}{2}-\sqrt{\left(\frac{\sigma_{2 x x}-\sigma_{2 y y}}{2}\right)^{2}+\sigma_{2 x y}^{2}}<-T_{2} \\
\sigma_{x y}>\sigma_{y y} \tan \varphi_{\mathrm{s}}+C_{\mathrm{s}} \\
\sigma_{y y}>-T_{\mathrm{s}}
\end{array}\right\}
$$
Type $A_{12}+$ Type $B$

$$
\left.\begin{array}{l}
\frac{\sigma_{1 x x}+\sigma_{1 y y}}{2}-\sqrt{\left(\frac{\sigma_{1 x x}-\sigma_{1 y y}}{2}\right)^{2}+\sigma_{1 x y}^{2}}<-T_{1} \\
\frac{\sigma_{2 x x}+\sigma_{2 y y}}{2}-\sqrt{\left(\frac{\sigma_{2 x x}-\sigma_{2 y y}}{2}\right)^{2}+\sigma_{2 x y}^{2}}<-T_{2} \\
\sigma_{x y}<\sigma_{y y} \tan \varphi_{\mathrm{s}}+C_{\mathrm{s}} \\
\sigma_{y y}<-T_{\mathrm{s}}
\end{array}\right\}
$$
Type $\mathrm{A}_{12}+$ Type $\mathrm{C}$

$$
\left.\begin{array}{l}
\frac{\sigma_{1 x x}+\sigma_{1 y y}}{2}-\sqrt{\left(\frac{\sigma_{1 x x}-\sigma_{1 y y}}{2}\right)^{2}+\sigma_{1 x y}^{2}}>-T_{1} \\
\frac{\sigma_{2 x x}+\sigma_{2 y y}}{2}-\sqrt{\left(\frac{\sigma_{2 x x}-\sigma_{2 y y}}{2}\right)^{2}+\sigma_{2 x y}^{2}}>-T_{2} \\
\sigma_{x y}>\sigma_{y y} \tan \varphi_{\mathrm{s}}+C_{\mathrm{s}} \\
\sigma_{y y}<-T_{\mathrm{s}}
\end{array}\right\} \quad \text { Type B + Type C }
$$

$$
\left.\begin{array}{l}
\frac{\sigma_{1 x x}+\sigma_{1 y y}}{2}-\sqrt{\left(\frac{\sigma_{1 x x}-\sigma_{1 y y}}{2}\right)^{2}+\sigma_{1 x y}^{2}}<-T_{1} \\
\frac{\sigma_{2 x x}+\sigma_{2 y y}}{2}-\sqrt{\left(\frac{\sigma_{2 x x}-\sigma_{2 y y}}{2}\right)^{2}+\sigma_{2 x y}^{2}}<-T_{2} \\
\sigma_{x y}>\sigma_{y y} \tan \varphi_{\mathrm{s}}+C_{\mathrm{s}} \\
\sigma_{y y}<-T_{\mathrm{s}}
\end{array}\right\} \text { Type } \mathrm{A}_{12}+\text { Type B + Type C }
$$


$\left.\begin{array}{l}\frac{\sigma_{1 x x}+\sigma_{1 y y}}{2}-\sqrt{\left(\frac{\sigma_{1 x x}-\sigma_{1 y y}}{2}\right)^{2}+\sigma_{1 x y}^{2}}>-T_{1} \\ \frac{\sigma_{2 x x}+\sigma_{2 y y}}{2}-\sqrt{\left(\frac{\sigma_{2 x x}-\sigma_{2 y y}}{2}\right)^{2}+\sigma_{2 x y}^{2}}<-T_{2} \\ \sigma_{x y}>\sigma_{y y} \tan \varphi_{\mathrm{s}}+C_{\mathrm{s}} \\ \sigma_{y y}>-T_{\mathrm{s}}\end{array}\right\}$ Type $\mathrm{A}_{2}+$ Type $\mathrm{B}$

$$
\left.\begin{array}{l}
\frac{\sigma_{1 x x}+\sigma_{1 y y}}{2}-\sqrt{\left(\frac{\sigma_{1 x x}-\sigma_{1 y y}}{2}\right)^{2}+\sigma_{1 x y}^{2}}>-T_{1} \\
\frac{\sigma_{2 x x}+\sigma_{2 y y}}{2}-\sqrt{\left(\frac{\sigma_{2 x x}-\sigma_{2 y y}}{2}\right)^{2}+\sigma_{2 x y}^{2}}<-T_{2} \\
\sigma_{x y}<\sigma_{y y} \tan \varphi_{\mathrm{s}}+C_{\mathrm{s}} \\
\sigma_{y y}<-T_{\mathrm{s}}
\end{array}\right\} \text { Type } \mathrm{A}_{2}+\text { Type } \mathrm{C}
$$

$$
\left.\begin{array}{l}
\frac{\sigma_{1 x x}+\sigma_{1 y y}}{2}-\sqrt{\left(\frac{\sigma_{1 x x}-\sigma_{1 y y}}{2}\right)^{2}+\sigma_{1 x y}^{2}}>-T_{1} \\
\frac{\sigma_{2 x x}+\sigma_{2 y y}}{2}-\sqrt{\left(\frac{\sigma_{2 x x}-\sigma_{2 y y}}{2}\right)^{2}+\sigma_{2 x y}^{2}}<-T_{2} \\
\sigma_{x y}>\sigma_{y y} \tan \varphi_{\mathrm{s}}+C_{\mathrm{s}} \\
\sigma_{y y}<-T_{\mathrm{s}}
\end{array}\right\} \text { Type } \mathrm{A}_{2}+\text { Type B + Type C }
$$

$$
\left.\begin{array}{l}
\frac{\sigma_{1 x x}+\sigma_{1 y y}}{2}-\sqrt{\left(\frac{\sigma_{1 x x}-\sigma_{1 y y}}{2}\right)^{2}+\sigma_{1 x y}^{2}}<-T_{1} \\
\frac{\sigma_{2 x x}+\sigma_{2 y y}}{2}-\sqrt{\left(\frac{\sigma_{2 x x}-\sigma_{2 y y}}{2}\right)^{2}+\sigma_{2 x y}^{2}}>-T_{2} \\
\sigma_{x y}>\sigma_{y y} \tan \varphi_{\mathrm{s}}+C_{\mathrm{s}} \\
\sigma_{y y}>-T_{\mathrm{s}}
\end{array}\right\} \text { Type } \mathrm{A}_{1}+\text { Type B }
$$

$$
\left.\begin{array}{l}
\frac{\sigma_{1 x x}+\sigma_{1 y y}}{2}-\sqrt{\left(\frac{\sigma_{1 x x}-\sigma_{1 y y}}{2}\right)^{2}+\sigma_{1 x y}^{2}}<-T_{1} \\
\frac{\sigma_{2 x x}+\sigma_{2 y y}}{2}-\sqrt{\left(\frac{\sigma_{2 x x}-\sigma_{2 y y}}{2}\right)^{2}+\sigma_{2 x y}^{2}}>-T_{2} \\
\sigma_{x y}<\sigma_{y y} \tan \varphi_{\mathrm{s}}+C_{\mathrm{s}} \\
\sigma_{y y}<-T_{\mathrm{s}}
\end{array}\right\} \text { Type } \mathrm{A}_{1}+\text { Type } \mathrm{C}
$$

$$
\left.\begin{array}{l}
\frac{\sigma_{1 x x}+\sigma_{1 y y}}{2}-\sqrt{\left(\frac{\sigma_{1 x x}-\sigma_{1 y y}}{2}\right)^{2}+\sigma_{1 x y}^{2}}<-T_{1} \\
\frac{\sigma_{2 x x}+\sigma_{2 y y}}{2}-\sqrt{\left(\frac{\sigma_{2 x x}-\sigma_{2 y y}}{2}\right)^{2}+\sigma_{2 x y}^{2}}>-T_{2} \\
\sigma_{x y}>\sigma_{y y} \tan \varphi_{\mathrm{s}}+C_{\mathrm{s}} \\
\sigma_{y y}<-T_{\mathrm{s}}
\end{array}\right\} \text { Type } \mathrm{A}_{1}+\text { Type B + Type C }
$$

\section{Analysis of the stability of the formation interface}

The stability of the formation interface under the impact of nearby hydraulic fracture propagation with different conditions was analyzed based on the stress-field distribution at the interface and the corresponding criteria for the classification of fracture propagation. The stability of the formation interface refers to whether the interface is displaced and whether the upper and lower sides of the rock are failed. Therefore, by analyzing whether the formation interface is displaced and the rock is failed, the stability of the formation interface can be obtained. Considering that the rocks above and below the formation interface had different mechanical properties and stresses (Zhang and Jeffrey 2007), some variables were analyzed for their impact on its stability based on the setting for basic parameters given in Tables 1 and 3 .

\subsection{Impact of rock mechanical properties on the shear and tensile failure modes of the formation interface}

Table 4 shows Young's modulus of the rocks at the two sides of the formation interface simulated for the analysis. The magnitude and direction of the peak stress at the formation interface at different Young's modulus values of the rock below the formation interface were simulated and computed. On this basis and according to the criteria for fracture propagation classification, the stability of the formation interface under the impact of hydraulic fracture propagation near the formation interface was analyzed.

The computational results (Fig. 18) show that, as Young's modulus $E$ of the rock below the formation interface

Table 3 Basic parameters for computation of hydraulic fracture propagation near the formation interface

Distance between the hydraulic fracture and the formation interface $C, \mathrm{~m}$ 
increases, the formation interface is stable and then experiences the following modes of failure in sequence: Type $B$ failure, Type $A_{1}+$ Type $B$ failure, Type $A_{12}+$ Type $B$ failure, Type $A_{2}+$ Type $B$ failure, Type $A_{2}+$ Type $\mathrm{B}+$ Type $\mathrm{C}$ failure, and Type $\mathrm{B}+$ Type $\mathrm{C}$ failure. When $E_{1}<12,000 \mathrm{MPa}$, the formation interface is stable. When $12,000 \leq E_{1}<15,000$, the shear stress acting on the formation interface exceeds the critical shear strength, and a slip occurs. When $15,000 \leq E_{1}<16,000$, the maximum tensile strength acting on the upper side of the formation interface exceeds the critical shear strength of the rock above, a slip occurs, and tensile failure occurs in the rock above. When $16,000 \leq E_{1}<28,000$, the maximum tensile stress acting on the lower side of the formation interface exceeds the critical tensile strength of the rock below, a slip occurs, and tensile failure occurs in the rock below. When $28,000 \leq E_{1}<30,000$, the maximum tensile strength acting on the lower side of the formation interface is smaller than the critical tensile strength of the rock below the formation interface, a slip occurs, and the tensile failure occurs in the rock above. When $30,000 \leq E_{1}<50,000$, the normal tensile stress acting on the formation interface exceeds its critical tensile strength, a slip occurs with tensile failure appears in the rock above. When $E_{1} \geq 50,000$, the maximum tensile strength acting on the upper side of the formation interface is smaller than the critical tensile strength of the rock above, and a slip and tensile failure occur.

The analysis reveals that, as Young's modulus of the rock below the formation interface increases, the formation interface is more prone to slipping than tensile failure. Whether the rocks at its two sides experience tensile failure depends on the tensile strength of the rock matrix and the direction of the maximum tensile stress. As Young's modulus of the rock below the formation interface increases, the complexity of the failure of the formation interface first increases, peaks when the rocks above and below have similar Young's moduli, and then decreases. This indicates that, either the hydraulic fracture is propagating in the pay layer or the barrier bed, a big difference in Young's modulus between the rocks above and below the formation interface serves to inhibit the initiation of new fractures at its two sides.

\subsection{Shear and tensile failure modes of the formation interface at different dip angles}

The magnitude and direction of the peak stress at the formation interface at different dip angles were simulated and analyzed. Its stability under the impact of nearby hydraulic fracture propagation was then analyzed.

The results (Fig. 19) show that, as the dip angle $\beta$ increases, the formation interface is stable, experiences the following modes of failure, and recovers stability: 


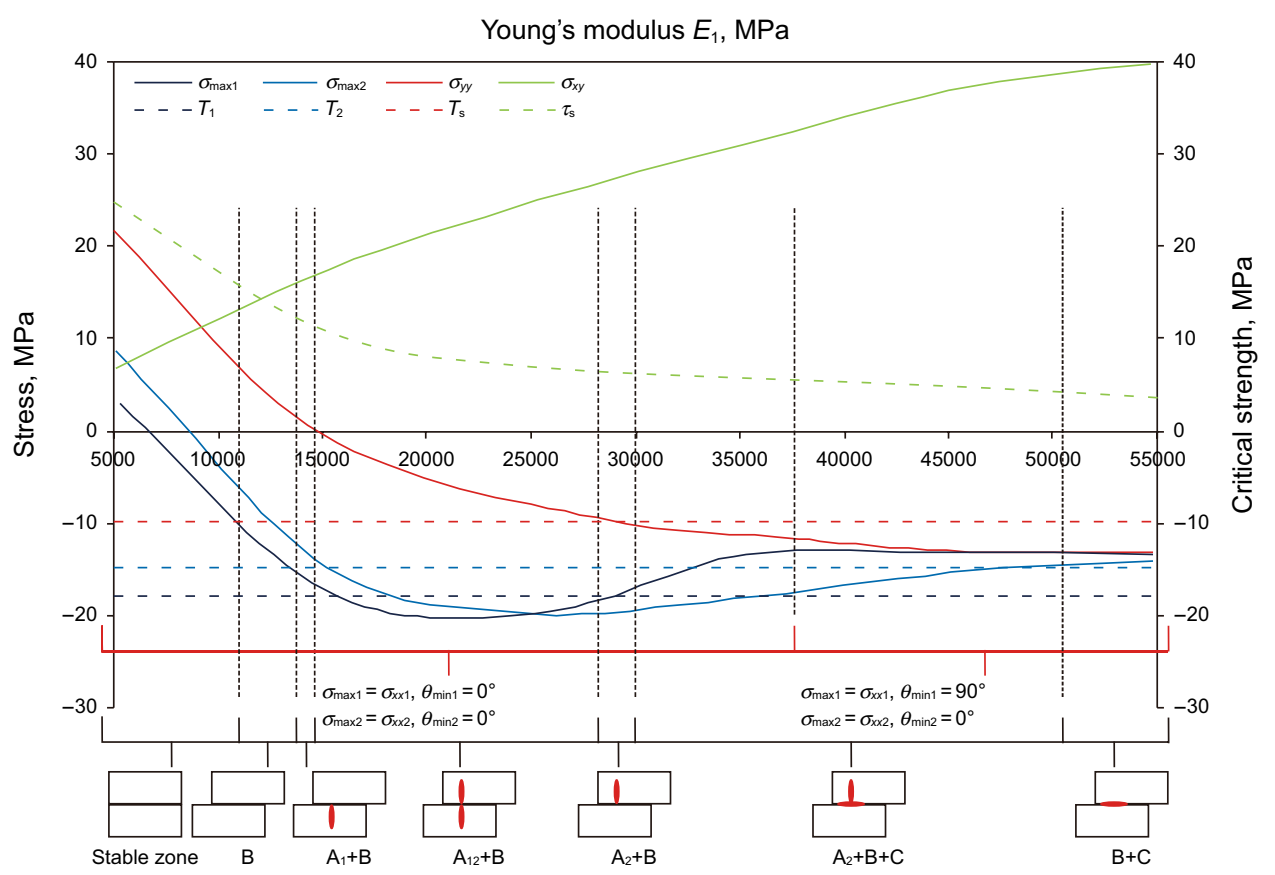

Fig. 18 Shear and tensile failure modes of the formation interface under the impact of hydraulic fracture propagation near the formation interface at different Young's moduli of the rock below the formation interface

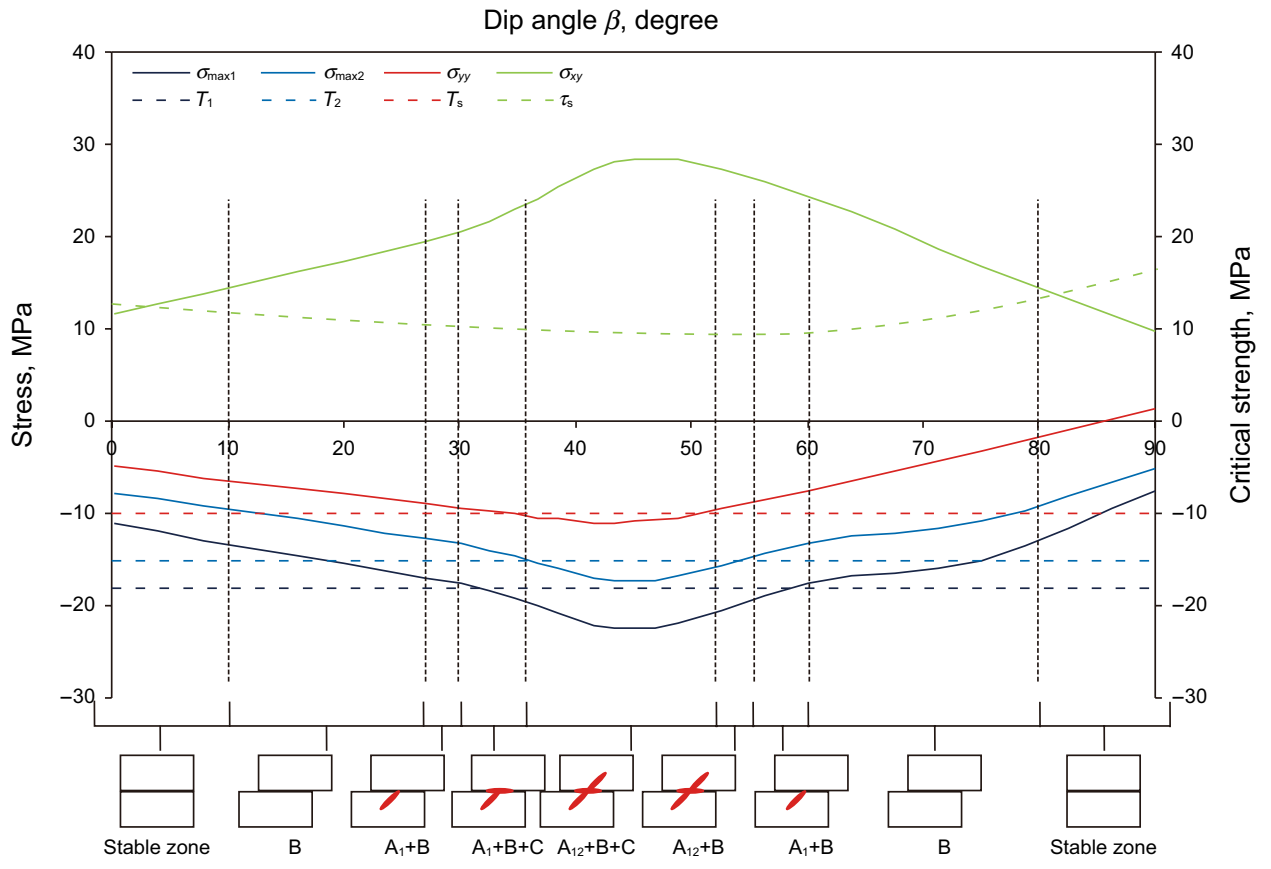

Fig. 19 Shear and tensile failure modes of the formation interface under the impact of hydraulic fracture propagation near the formation interface at different dip angles

Type $B$ failure, Type $A_{1}+$ Type $B$ failure, Type $A_{1}+$ Type $B+$ Type $C$ failure, Type $A_{12}+$ Type $B+$ Type $C$ failure, Type $A_{12}+$ Type $B$ failure, Type $A_{1}+$ Type $B$ failure, and
Type B failure. When $\beta<10^{\circ}$, the formation interface is stable. When $10^{\circ} \leq \beta<28^{\circ}$, the shear stress acting on the formation interface exceeds its critical shear strength, and 
a slip occurs. When $28^{\circ} \leq \beta<30^{\circ}$, the maximum tensile stress acting on the lower side of the formation interface exceeds the critical tensile strength of the rock below, a slip occurs, and tensile failure occurs in the rock below. When $30^{\circ} \leq \beta<36^{\circ}$, the normal tensile stress acting on the formation interface exceeds its critical tensile strength, a slip and tensile failure occur, and tensile failure occurs in the rock below. When $36^{\circ} \leq \beta<53^{\circ}$, the maximum tensile stress acting on the upper side of the formation interface exceeds the critical tensile strength of the rock above, a slip and tensile failure occur, and tensile failure occurs in the rock above. When $53^{\circ} \leq \beta<55^{\circ}$, the normal tensile stress acting on the formation interface is smaller than its critical tensile strength, a slip occurs, and tensile failure occurs in the rocks below and above. When $55^{\circ} \leq \beta<60^{\circ}$, the maximum tensile stress acting on the upper side of the formation interface is smaller than the critical tensile strength of the rock above, a slip occurs, and tensile failure occurs in the rock below. When $60^{\circ} \leq \beta<80^{\circ}$, the maximum tensile stress acting on the lower side of the formation interface is smaller than the critical tensile strength of the rock below, a slip occurs. When $\beta \geq 80^{\circ}$, the shear stress acting on it is smaller than its critical shear strength, and it does not fail.

The analysis reveals that, as the dip angle approximates $45^{\circ}$, a slip at the formation interface has a higher possibility of occurrence than tensile failure at the two sides, followed by tensile failure at the formation interface. As the dip angle increases, the complexity of failure at the formation interface first increases then decreases, exhibiting a roughly symmetric pattern around a dip angle of $45^{\circ}$. There, the hydraulic fracture is most likely to cross the formation interface.

\subsection{Shear and tensile failure modes of the formation interface at different distances to the hydraulic fracture}

The magnitude and direction of the peak stress at the formation interface at different distances, $C$, between it and the hydraulic fracture was simulated and computed. The results (Fig. 20) show that, as $C$ increases, the formation interface experiences the following different modes of failure in sequence and then recovers stability: Type $A_{12}+$ Type $\mathrm{B}+$ Type $\mathrm{C}$ failure, Type $\mathrm{A}_{12}$ + Type $\mathrm{B}$ failure, and Type $\mathrm{B}$ failure. When $C<0.65 \mathrm{~m}$, the normal tensile stress and shear stress acting on the formation interface and the maximum tensile stress acting on the rocks at its two sides are bigger than its corresponding critical strengths, a tensile and slip failure occurs, and tensile failure occurs in the rocks at the two sides. When $0.65 \mathrm{~m} \leq C<0.8 \mathrm{~m}$, the normal tensile stress acting on the formation interface is smaller than its critical tensile strength, a slip occurs at the information interface, and tensile failure occurs in the rocks at the two sides. When $0.8 \mathrm{~m} \leq C<0.97 \mathrm{~m}$, the maximum tensile stresses acting on the upper and lower sides of the formation interface are smaller than the critical tensile strengths of the rocks above and below the formation interface, and

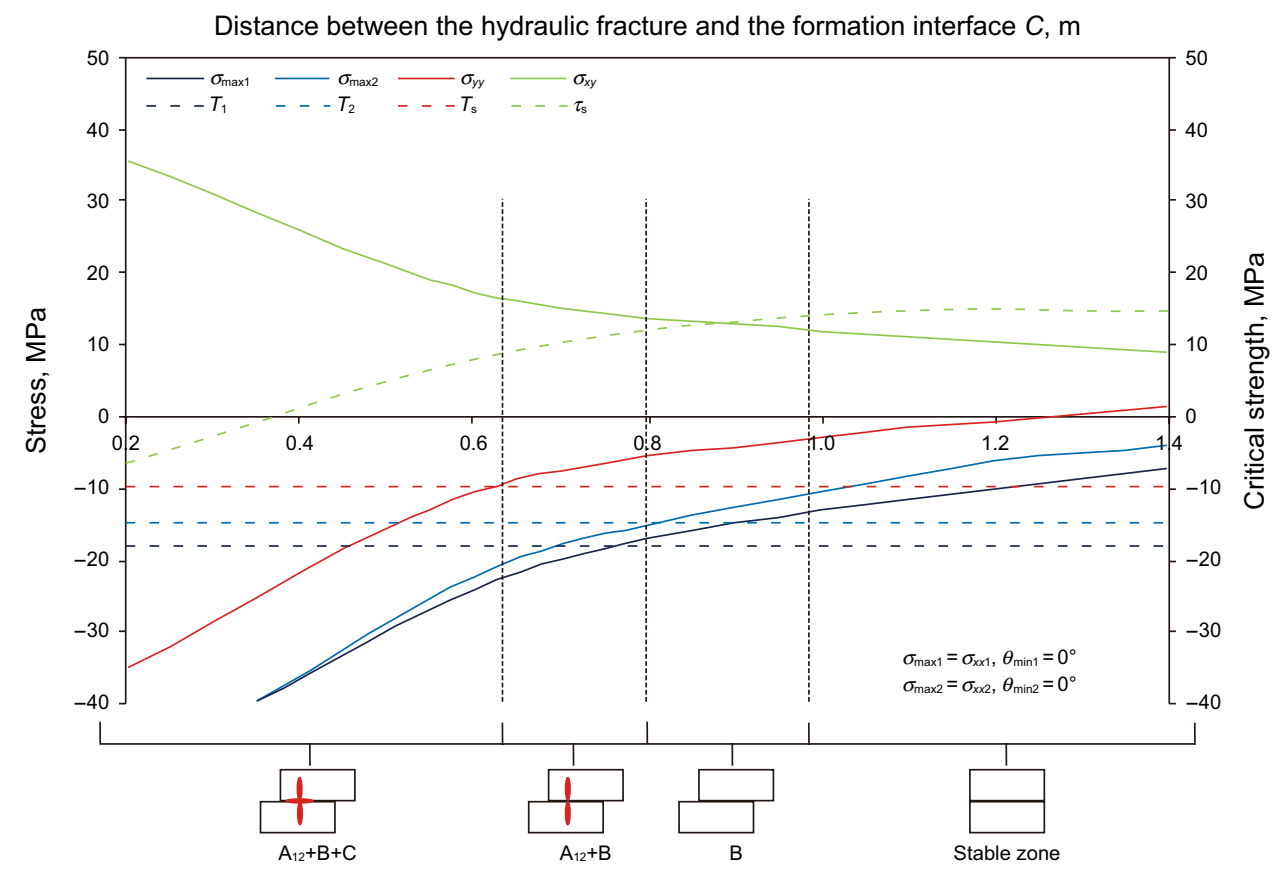

Fig. 20 Shear and tensile failure modes of the formation interface under the impact of hydraulic fracture propagation near the formation interface at different distances between the hydraulic fracture and the formation interface 


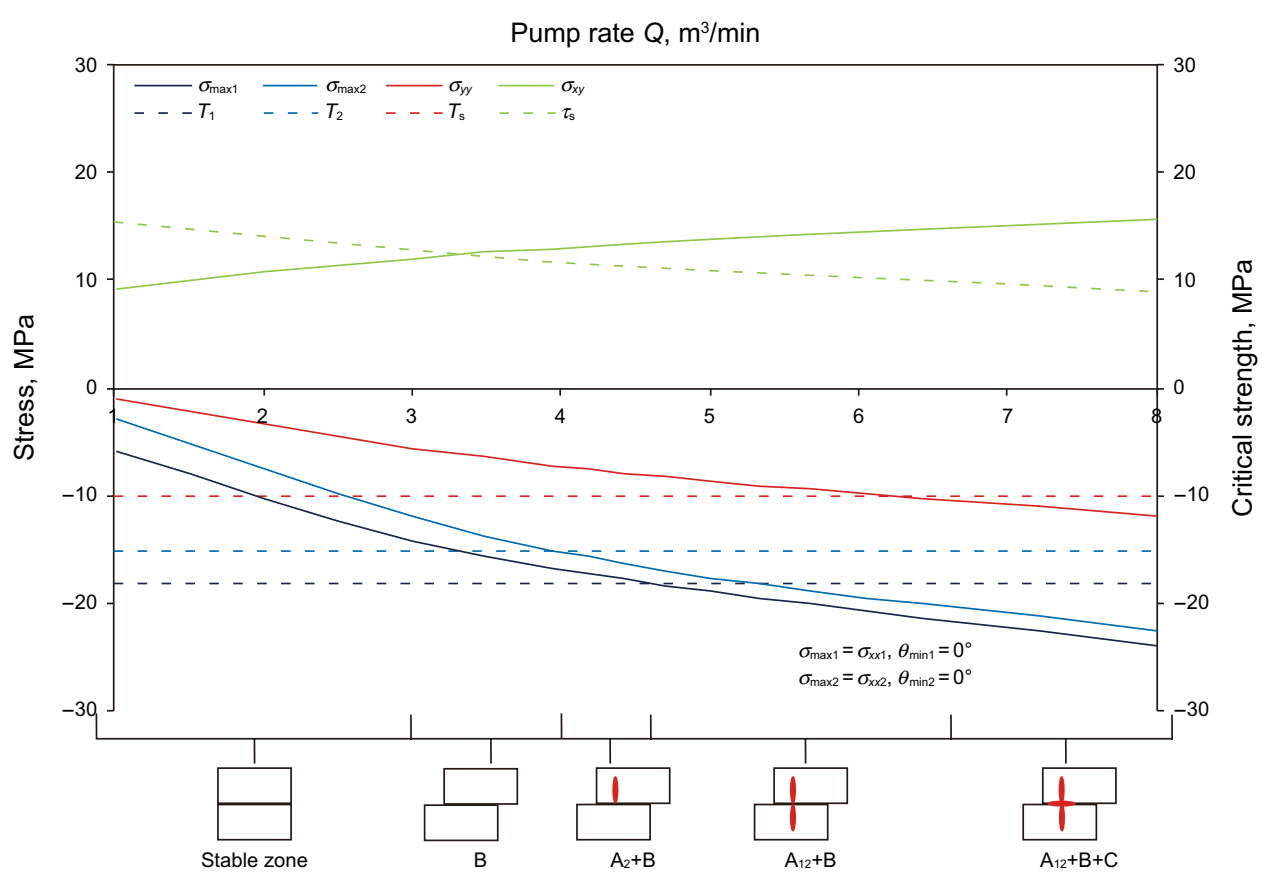

Fig. 21 Shear and tensile failure modes of the formation interface under the impact of hydraulic fracture propagation near the formation interface at different pump rates

slip occurs at the formation interface. When $C \geq 0.8 \mathrm{~m}$, the shear stress acting on the formation interface is smaller than its shear strength, and it does not fail.

The analysis reveals that, as the distance between the hydraulic fracture and the formation interface decreases, slip has a higher probability of occurrence than tensile failure in the rocks at the two sides, followed by tensile failure.

\subsection{Shear and tensile failure modes of the formation interface at different pump rates}

The magnitude and direction of the peak stress at the formation interface at different pump rates were simulated and computed. The results (Fig. 21) show that, as the pump rate, $Q$, increases, the formation interface is first stable and then experiences the following different modes of failure in sequence: Type $B$ failure, Type $A_{2}+$ Type $B$ failure, Type $\mathrm{A}_{12}+$ Type $\mathrm{B}$ failures, and Type $\mathrm{A}_{12}+$ Type $\mathrm{B}+$ Type $\mathrm{C}$ failure.

When $Q<3 \mathrm{~m}^{3} / \mathrm{min}$, the formation interface is stable. When $3 \mathrm{~m}^{3} / \mathrm{min} \leq Q<3.9 \mathrm{~m}^{3} / \mathrm{min}$, the shear stress acting on the formation interface exceeds its critical shear strength, and a slip occurs. When $3.9 \mathrm{~m}^{3} / \mathrm{min} \leq Q<4.5 \mathrm{~m}^{3} / \mathrm{min}$, the maximum tensile stress acting on the upper side of the formation interface exceeds the critical tensile strength of the rock above, a slip occurs, and tensile failure occurs in the rock above. When $4.5 \mathrm{~m}^{3} / \mathrm{min} \leq Q<6.4 \mathrm{~m}^{3} / \mathrm{min}$, the maximum tensile stress acting on the lower side of the formation interface exceeds the critical tensile strength of the rock below, a slip occurs, and tensile failure occurs in the rocks above and below. When $Q \geq 6.4 \mathrm{~m}^{3} / \mathrm{min}$, the normal tensile stress acting on the formation interface exceeds its critical tensile strength, a slip and tensile failure occurs, and tensile failure occurs in the rocks below and above.

The analysis reveals that, as the pump rate increases, a slip at the formation interface has a higher possibility of occurrence than tensile failure in the rock above, followed by tensile failure in the rock below and tensile failure at the interface. As the pump rate increases, the complexity of failure at the formation interface increases. For separatelayer fracturing at the formation interface, medium- to lowrate pumping is desirable for fracture height control, this means that with the simulation data of Fig. 21, the pump rate should be less than $3.9 \mathrm{~m}^{3} / \mathrm{min}$. For simultaneous fracturing of multiple thin layers, medium- to high-rate pumping is desirable for improving reservoir utilization, taking the data in Fig. 21 as an example, the pump rate should be greater than $4.5 \mathrm{~m}^{3} / \mathrm{min}$.

\section{Conclusions}

Criteria were proposed for determining the following four failure modes under the impact of hydraulic fracture propagation near the formation interface using the maximum 
normal stress intensity theory and the Mohr-Coulomb theory: tensile failure of rocks at either or both sides of the formation interface; shear failure at the formation interface; tensile failure at the formation interface; and complex failure.

The stress-field distribution in a layered formation under the impact of hydraulic fracture propagation near the formation interface is characterized by stress singularity and reversal. More specifically, the maximum normal stress field and normal stress field in the formation are symmetric. The shear stress field in the formation is antisymmetric. The maximum normal stress and normal stress field at the formation interface are symmetric with a single peak. The shear stress field is antisymmetric with a single peak, and the direction of minimum normal stress is antisymmetric.

When the pay layer and barrier bed are of different properties, the stress-change rate in the pay layer is bigger than that in the barrier bed. The maximum tensile stress at the pay-layer side of the formation interface is bigger than that at the barrier bedside. The major factors affecting the distribution and magnitude of the stress at the two sides of the formation interface include rock mechanical properties, distance between it formation interface and hydraulic fracture, and net pressure in the hydraulic fracture. The major factors affecting the stress-change rate at the two sides of the formation interface include rock mechanical properties and dip angle. The major factors affecting the discontinuity of the maximum normal stress at the two sides of the formation interface include rock mechanical properties.

At lower strengths of the formation interface, it fails before the growing hydraulic fracture is in contact. Its stability is significantly related to a variety of factors, including formation interface failure type, rock mechanical properties, far-field stress, structural parameters, distance between the formation interface and the hydraulic fracture, and fracturing execution parameters.

Acknowledgement This article was prepared under the auspices of the State Key Laboratory of Oil and Gas Reservoir Geology and Exploitation at Southwest Petroleum University and supported by National Natural Science Foundation of China (51704251), and National Science and Technology Major Project of the Ministry of Science and Technology of China (2016ZX05006-002).

Open Access This article is licensed under a Creative Commons Attribution 4.0 International License, which permits use, sharing, adaptation, distribution and reproduction in any medium or format, as long as you give appropriate credit to the original author(s) and the source, provide a link to the Creative Commons licence, and indicate if changes were made. The images or other third party material in this article are included in the article's Creative Commons licence, unless indicated otherwise in a credit line to the material. If material is not included in the article's Creative Commons licence and your intended use is not permitted by statutory regulation or exceeds the permitted use, you will need to obtain permission directly from the copyright holder. To view a copy of this licence, visit http://creativecommons.org/licenses/by/4.0/.

\section{References}

Anderson GD. Effects of friction on hydraulic fracture growth near unbonded interfaces in rocks. SPE J. 1981;21(1):21-9. https:// doi.org/10.2118/8347-PA.

Arash DT, Olson JE. How natural fractures could affect hydraulicfracture geometry. SPE J. 2013;19(01):161-71. https://doi. org/10.2118/167608-PA.

Biot MA, Medlin WL, Masse L. Fracture penetration through an interface. SPE J. 1983;23(6):857-69. https://doi.org/10.2118/10372 -PA.

Bunger AP, Zhang X, Jeffrey RG. Parameters affecting the interaction among closely spaced hydraulic fractures. SPE J. 2012;17(01):292-306. https://doi.org/10.2118/140426-PA.

Chen ZR, Jeffrey RG, Zhang X, Kear J. Finite-element simulation of a hydraulic fracture interacting with a natural fracture. SPE J. 2017;22(01):219-34. https://doi.org/10.2118/176970-PA.

Chuprakov DA, Prioul R. Hydraulic fracture height containment by weak horizontal interfaces. In: SPE Hydraulic fracturing technology conference. 2015. Texas, USA: The Woodlands; 2015. https ://doi.org/10.2118/173337-MS.

Cohen CE, Kresse O, Weng XW. Stacked height model to improve fracture height growth prediction, and simulate interactions with multi-layer DFNs and ledges at weak zone interfaces. In: SPE hydraulic fracturing technology conference and exhibition. Texas, USA: The Woodlands; 2017. https://doi.org/10.2118/184876-MS.

Damani A, Sondergeld CH, Rai CS. Experimental investigation of in situ and injection fluid effect on hydraulic fracture mechanism using acoustic emission in Tennessee sandstone. J Pet Sci Eng. 2018;171:315-24. https://doi.org/10.1016/j.petrol.2018.07.027.

Daneshy AA. Hydraulic fracture propagation in layered formations. SPE J. 1978;18(1):33-41. https://doi.org/10.2118/6088-PA.

Fan TY. Fundamentals of fracture mechanics. Nanjing: Jiangsu Science and Technology Press; 1978 (in Chinese).

Fisher MK, Warpinski NR. Hydraulic-fracture-height growth: real data. SPE Prod Oper. 2012;27(01):8-19. https://doi.org/10.2118/14594 9-PA.

Garavand A, Podgornov VM. Hydraulic fracture optimization by using a modified pseudo-3D model in multi-layered reservoirs. J Nat Gas Geosci. 2018;3(4):233-42. https://doi.org/10.1016/j.jnggs .2018.08.004.

Gu H, Weng X, Lund JB, Mack MG, Ganguly U, Suarez RR. Hydraulic fracture crossing natural fracture at nonorthogonal angles: a criterion and its validation. SPE Prod Oper. 2012;27(1):20-6. https ://doi.org/10.2118/139984-PA.

Guo JC, Luo B, Lu C, Lai J, Ren JC. Numerical investigation of hydraulic fracture propagation in a layered reservoir using the cohesive zone method. Eng Fract Mech. 2017;186:195-207. https ://doi.org/10.1016/j.engfracmech.2017.10.013.

Ham VE. Hydraulic fracture geometry: fracture containment in layered formations. SPE J. 1982;22(3):341-9.

Hanson ME, Shaffer RJ. Some results from continuum mechanics analyses of the hydraulic fracturing process. SPE J. 1980;20(2):86-94. https://doi.org/10.2118/7942-PA.

He MY, Hutchinson JW. Crack deflection at an interface between dissimilar elastic materials. Int J Solids Struct. 1989;25(9):1053-67. https://doi.org/10.1016/0020-7683(89)90021-8.

Irwin GR. Analysis of stresses and strains near the end of a crack traversing a plate. J Appl Mech Trans. 1957;E24:361-4.

Izadi G, Moos D, Cruz L, Gaither M, Chiaramonte L, Johnson S. Fully coupled 3-D hydraulic fracture growth in the presence of weak horizontal interfaces. In: SPE hydraulic fracturing technology conference and exhibition. 24-26 January. Texas, USA: The Woodlands; 2017. https://doi.org/10.2118/184854-MS. 
Jeffrey RG, Bunger A. A detailed comparison of experimental and numerical data on hydraulic fracture height growth through stress contrasts. SPE J. 2009;14(03):413-22. https://doi. org/10.2118/106030-PA.

Kuang ZB, Ma FS. Crack tip fields. Xi' an: Xi' an Jiaotong University Press; 2002 (in Chinese).

Li YW, Rui ZH, Zhao WC, Bo YH, Fu CK, Chen G, Patil S. Study on the mechanism of rupture and propagation of T-type fractures in coal fracturing. J Nat Gas Sci Eng. 2018;52:379-89. https://doi. org/10.1016/j.jngse.2018.01.010.

Liu YS, Fu HL, Wu YM, He YW, Dong H. Study on Brazilian splitting test for slate based on single weak plane theory. J Coal Sci. 2013;38(10):1775-80 (in Chinese).

Lu C, Li M, Guo JC, Tang XH, Zhu HY, Wang YH, Liang H. Engineering geological characteristics and the hydraulic fracture propagation mechanism of the sand-shale interbedded formation in the Xu5 reservoir. J Geophys Eng. 2015;12(3):321-39. https://doi. org/10.1088/1742-2132/12/3/321.

Lu C, Guo JC, Liu LM. A new calculation model for the stress field of hydraulic fracture propagation at the formation interface. Environ Earth Sci. 2016;75(16):1178. https://doi.org/10.1007/s 1266 5-016-5947-0.

Ouchi H, Agrawal S, Foster JT, Sharma MM. Effect of small scale heterogeneity on the growth of hydraulic fractures. In: SPE hydraulic fracturing technology conference and exhibition. 24-26 January. Texas, USA: The Woodlands; 2017a. https://doi. org/10.2118/184873-MS.

Ouchi H, Foster JT, Sharma MM. Effect of reservoir heterogeneity on the vertical migration of hydraulic fractures. J Pet Sci Eng. 2017;151:384-408. https://doi.org/10.1016/j.petrol.2016.12.034.

Oyedokun O, Schubert J. A quick and energy consistent analytical method for predicting hydraulic fracture propagation through heterogeneous layered media and formations with natural fractures: the use of an effective fracture toughness. J Nat Gas Sci Eng. 2017;44:351-64. https://doi.org/10.1016/j.jngse.2017.05.001.

Paul B, et al. 3D coupled HM-XFEM modeling with cohesive zone model and applications to non-planar hydraulic fracture propagation and multiple hydraulic fractures interference. Comput Methods Appl Mech Eng. 2018;342:321-53. https://doi.org/10.1016/j. cma.2018.08.009.

Renshaw CE, Pollard DD. An experimentally verified criterion for propagation across unbounded frictional interfaces in brittle, linear elastic materials. Int J Rock Mech Min Sci Geomech Abstr.
1995;32(3):237-49. https://doi.org/10.1016/0148-9062(94)00037 $-4$.

Rutledge J, Yu X, Leaney S, Bennett L, Maxwell S. Microseismic shearing generated by fringe cracks and bedding-plane slip. In: 2014 SEG annual meeting. 26-31 October. Denver, Colorado, USA; 2014. https://doi.org/10.1190/segam2014-0896.1.

Tang JZ, Wu K. A 3-D model for simulation of weak interface slippage for fracture height containment in shale reservoirs. Int J Solids Struct. 2018;144-145:248-64. https://doi.org/10.1016/j.ijsol str.2018.05.007.

Tang XH, Rutqvist J, Hu MS, Rayudu NM. Modeling three-dimensional fluid-driven propagation of multiple fractures using TOUGH-FEMM. Rock Mech Rock Eng. 2019;52(2):611-27. https://doi.org/10.1007/s00603-018-1715-7.

Wang HY. Numerical modeling of non-planar hydraulic fracture propagation in brittle and ductile rocks using XFEM with cohesive zone method. J Pet Sci Eng. 2015;135:127-40. https://doi. org/10.1016/j.petrol.2015.08.010.

Wang H, Liu H, Wu HA, Wang XX. A 3D numerical model for studying the effect of interface shear failure on hydraulic fracture height containment. J Pet Sci Eng. 2015;133:280-4. https://doi. org/10.1016/j.petrol.2015.06.016.

Warpinski NR, Teufel LW. Influence of geologic discontinuities on hydraulic fracture propagation. J Pet Technol. 1987;39(2):209-20. https://doi.org/10.2118/13224-PA.

Wu H, Chudnovsky A, Dudley JW, Wong GK. A map of fracture behavior in the vicinity of an interface. In: Gulf rocks 2004, the 6th North America Rock mechanics symposium. 5-9 June. Houston, Texas; 2004. ARMA-04-620.

Xie HP, Chen ZH. Rock mechanics. Beijing: Science Press; 2004 (in Chinese).

Zeng QD, Liu WD, Yao J. Numerical modeling of multiple fractures propagation in anisotropic formation. J Nat Gas Sci Eng. 2018;53:337-46. https://doi.org/10.1016/j.jngse.2018.02.035.

Zhang X, Jeffrey RG. Hydraulic fracture propagation across frictional interfaces. In: 1st Canada-U.S. rock mechanics symposium. 27-31 May. Vancouver, Canada; 2007. ARMA-07-204.

Zhang X, Wu B, Connell LD, Han Y, Jeffrey RG. A model for hydraulic fracture growth across multiple elastic layers. J Pet Sci Eng. 2018;167:918-28. https://doi.org/10.1016/j.petrol.2018.04.071.

Zhao HF, Chen M, Jin Y. Extending behavior of hydraulic fracture on formation interface. Acta Pet Sin. 2009;30(03):450-4. https://doi. org/10.7623/syxb200903025 (in Chinese). 